\title{
North American Supercell Environments in Atmospheric Reanalyses and RUC-2
}

\author{
Austin T. King And AARON D. KenNedy \\ Department of Atmospheric Sciences, University of North Dakota, Grand Forks, North Dakota
}

(Manuscript received 18 January 2018, in final form 20 July 2018)

\begin{abstract}
A suite of modern atmospheric reanalyses is analyzed to determine how they represent North American supercell environments. This analysis is performed by comparing a database of Rapid Update Cycle (RUC-2) proximity soundings with profiles derived from the nearest grid point in each reanalysis. Parameters are calculated using the Sounding and Hodograph Analysis and Research Program in Python (SHARPpy), an open-source Python sounding-analysis package. Representation of supercell environments varies across the reanalyses, and the results have ramifications for climatological studies that use these datasets. In particular, thermodynamic parameters such as the convective available potential energy (CAPE) show the widest range in biases, with reanalyses falling into two camps. The North American Regional Reanalysis (NARR) and the Japanese 55-year Reanalysis (JRA-55) are similar to RUC-2, but other reanalyses have a substantial negative bias. The reasons for these biases vary and range from thermodynamic biases at the surface to evidence of convective contamination. Overall, it is found that thermodynamic biases feed back to other convective parameters that incorporate CAPE directly or indirectly via the effective layer. As a result, significant negative biases are found for indices such as the supercell composite parameter. These biases are smallest for NARR and JRA-55. Kinematic parameters are more consistent across the reanalyses. Given the issues with thermodynamic properties, better segregation of soundings by storm type is found for fixed-layer parameters than for effective-layer shear parameters. Although no reanalysis can exactly reproduce the results of earlier RUC-2 studies, many of the reanalyses can broadly distinguish between environments that are significantly tornadic versus nontornadic.
\end{abstract}

\section{Introduction}

Atmospheric reanalyses combine historical observations with a fixed data assimilation scheme and underlying model to achieve a dynamically consistent, gridded representation of the atmosphere. This process fills data-void regions, and for this reason, reanalyses are commonly used to investigate various questions related to past weather events and climate. For example, reanalyses have shed light on the climatology and trends of severe weather environments, that is, environments with conditions favorable for severe weather, given the numerous issues with observed reports associated with these events (e.g., Brooks et al. 2003, 2007; Gensini and Ashley 2011; Romero et al. 2007; Blamey et al. 2016). Based off this climatological work, reanalyses have also been used to assess the fidelity of these environments in climate simulations (Marsh et al. 2007; Trapp et al. 2007; Gensini et al. 2014b). In summary, reanalyses are a key

Corresponding author: Aaron David Kennedy, kennedya@aero. und.edu piece of the puzzle to determine how severe weather events may or may not change in a warming climate.

Since reanalyses are run at resolutions inadequate to resolve the processes that dictate severe weather events, alternative methods must be employed to relate reanalysis output to the potential for severe weather. One such way is to identify favorable environments by calculating diagnostic sounding parameters such as convective available potential energy (CAPE) and bulk wind difference (BWD) from reanalyzed vertical profiles of the atmosphere.

Parameter-based evaluation of severe weather environments is rooted in earlier forecasting studies that utilized observed proximity soundings to discriminate between types of convection or the phenomenon produced (e.g., Davies 1993; Johns et al. 1993; Rasmussen and Blanchard 1998; Rasmussen 2003). Ideally, these soundings should be taken within the inflow environment of the storm, but this can significantly limit the number of samples for analysis. Further, there is risk of limiting the representativeness of the sounding due to interference from the storm itself (socalled convective contamination). 
In lieu of observed soundings, the rise of mesoscale models has led to analyzed or forecast soundings being used as pseudo-/proximity soundings for convective events, significantly increasing the number of samples for any given study (Markowski et al. 2003; Thompson et al. 2003, hereinafter T03, 2007, hereinafter T07; Davies 2004; Reames 2017). T03 found that Rapid Update Cycle-2 (RUC-2; Benjamin et al. 2004) soundings were a good proxy for observed soundings and contained errors that were generally "within $0.5^{\circ} \mathrm{C}$ for temperatures, $0.2 \mathrm{~g} \mathrm{~kg}^{-1}$ for mixing ratios, and $1 \mathrm{~m} \mathrm{~s}^{-1}$ for wind speed (all close to the ranges for radiosonde accuracy)." This resulted in a mixed-layer CAPE (MLCAPE) bias that was slightly positive $\left(62 \mathrm{~J} \mathrm{~kg}^{-1}\right)$ when averaged across 0 - $\mathrm{h}$ analyses and 1 -h forecast soundings within the dataset. This positive bias $\left(\sim 150 \mathrm{~J} \mathrm{~kg}^{-1}\right)$ was also noted by Coniglio (2012), who compared proximity soundings from RUC-2 and the Storm Prediction Center operational surface objective analysis system (SFCOA) with radiosonde observations from the Second Verification of the Origins of Rotation in Tornadoes Experiment (VORTEX2). While no model is perfect, T03 concluded that, "Overall, the RUC-2 analysis soundings appear to be a reasonable proxy for observed soundings in supercell environments."

Given this information, it seems plausible that reanalyses can provide pseudo-/proximity soundings (hereinafter proximity soundings) for convective events, especially for regions with ample observations. This concept was used by Brooks et al. (2003), who analyzed environments in the NCEP-NCAR (Kalnay et al. 1996) reanalysis to determine the frequency of environments favorable for severe thunderstorms over North America and Europe. Despite being coarse relative to the latest generation of reanalyses $(\sim 200-\mathrm{km}$ horizontal grid spacing, 28 vertical levels, and 6-hourly increments) this dataset allowed for proximity soundings to be taken within previously used definitions, such as within $3 \mathrm{~h}$ and $180 \mathrm{~km}$ of an event (T03). Overall, the reanalysisderived frequencies displayed many similarities with observed severe weather occurrence such as regional maxima over the central United States and near the Mediterranean Sea. This concept was expanded on by Brooks et al. (2007) and Brooks (2009), who examined the annual cycle and efficiency of severe weather environments from the NCEP-NCAR reanalysis. They found that ingredients favorable for severe weather exist over a longer period of time in the central United States whereas southeastern U.S. and European environments are more similar. They noted regional differences have ramifications for both forecasting and for addressing how frequencies may change in the future. To address this latter question, Marsh et al. $(2007,2009)$ extended this framework to simulated soundings from the
Community Climate System Model, version 3 (CCSM3), to investigate North American and European severe weather environments in past and future climates. Although CCSM3 had a negative bias in environments, it was able to capture spatial and temporal variability seen in the NCEP-NCAR global reanalysis. Future simulations suggested that Europe would see an increase in environments favorable for severe weather.

Since these earlier studies, a number of reanalyses now exist, which leads one to ponder whether severe weather environments are similar among these datasets. Overall, the capability of these reanalyses in representing these environments is somewhat unclear. Kennedy et al. (2011) demonstrated that large differences in the vertical profiles of variables can exist between reanalyses, specifically the North American Regional Reanalysis (NARR; Mesinger et al. 2006) and the Modern-Era Retrospective Analysis for Research and Applications (MERRA; Rienecker et al. 2011). This suggests that derived sounding parameters that are useful for investigating convective events may differ significantly among reanalyses. This clouds the utility of these datasets for applied forecasting and climatological studies.

Although some work has been done to clarify this ambiguity in the representation of severe weather environments, most studies have focused on the NARR. Gensini et al. (2014a) noted that kinematic variables were best represented by this reanalysis, while thermodynamic variables were generally overestimated and had regional biases. This study also demonstrated that sharp gradients in temperature that were associated with the elevated mixed layer were not adequately resolved by NARR in most soundings. In a study of high-CAPE, low-shear severe weather events, Sherburn et al. (2016) found that surface-based CAPE (SBCAPE) calculated from the NARR did not strongly correlate with SBCAPE from the SFCOA. In addition, the NARR overestimated SBCAPE in comparison with this analysis system.

While the error characteristics of the NARR with regard to severe weather parameters have been relatively well documented, a comprehensive study of all currentgeneration reanalyses has never been completed. Many of these other reanalyses have been used in past studies to identify regional properties or trends in severe weather parameters. This has been done without knowledge of the capability of the reanalysis in representing severe weather environments, at least in comparison to other reanalysis datasets. For example, Blamey et al. (2016) used the Climate Forecast System Reanalysis (CFSR) to examine trends in severe weather over South Africa, and Allen and Karoly (2014) performed a similar analysis with the European Centre for Medium-Range Forecasts (ECMWF) interim reanalysis (ERA-Interim; Dee et al. 2011) to 


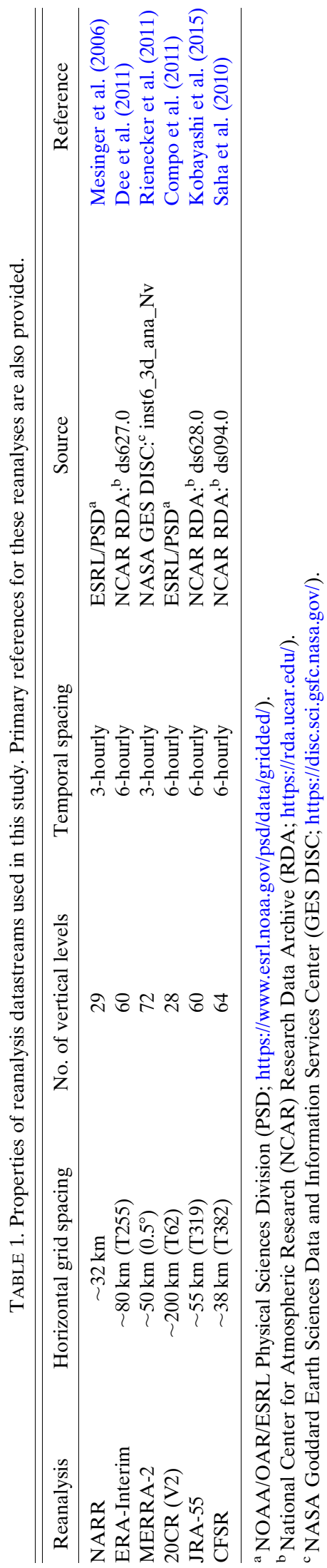

TABLE 2. List of calculated sounding parameters provided by SHARPpy and used in this study. Details for these parameters are found in Blumberg et al. (2017).

\begin{tabular}{|c|c|c|}
\hline Parameter & Notation & Types and abbreviations \\
\hline \multicolumn{3}{|c|}{ Kinematic } \\
\hline Helicity & HEL & $0-1-\mathrm{km}(1 \mathrm{~km})$ \\
\hline Storm-relative helicity & SRH & $0-3-\mathrm{km}(3 \mathrm{~km})$ \\
\hline Bulk wind difference & BWD & Effective layer (E) \\
\hline \multicolumn{3}{|c|}{ Thermodynamic } \\
\hline $\begin{array}{l}\text { Convective available } \\
\text { potential energy }\end{array}$ & CAPE & Surface based (SB) \\
\hline Convective inhibition & CIN & Mixed layer (ML) \\
\hline Lifted condensation level & $\mathrm{LCL}$ & Most unstable (MU) \\
\hline \multicolumn{3}{|c|}{ Composite } \\
\hline $\begin{array}{l}\text { Supercell composite } \\
\text { parameter }\end{array}$ & SCP & Fixed layer (fixed) \\
\hline $\begin{array}{l}\text { Significant tornado } \\
\text { parameter }\end{array}$ & STP & Effective layer (CIN) \\
\hline
\end{tabular}

determine the interannual variability and influence of El Niño-Southern Oscillation on severe thunderstorms in Australia. ERA-Interim has also been used to investigate the relationship of rainfall extremes to atmospheric properties (Lepore et al. 2015). It is possible that the use of a different reanalysis could have produced different results for any of these studies.

Given this discussion, the primary goal of this study is to identify the characteristics of environments commonly associated with severe weather in the latest generation of atmospheric reanalyses. To do so, these datasets will be compared with a database of RUC-2 proximity soundings from T03 and T07 that predominately represent North American supercell environments. Beyond identifying characteristics of common severe weather parameters, this effort will explore whether reanalyses can reproduce earlier work from T03 and T07.

To briefly recap these earlier studies, T03 and T07 demonstrated that certain sounding parameters have skill in identifying environments supportive of supercells and tornadoes. In T03, relationships between storm categories and thermodynamic and kinematic parameters led to the development of the supercell composite parameter (SCP) and significant tornado parameter (STP), which are used operationally to help discriminate between environments. T07 defined the effective (layer) storm-relative helicity (ESRH) and found it is more appropriate in discriminating between tornadic and nontornadic environments than its counterpart storm-relative helicity (SRH), which does not take the effective inflow-layer depth into account. The question remains whether these findings can be duplicated with proximity soundings from reanalyses. 
A

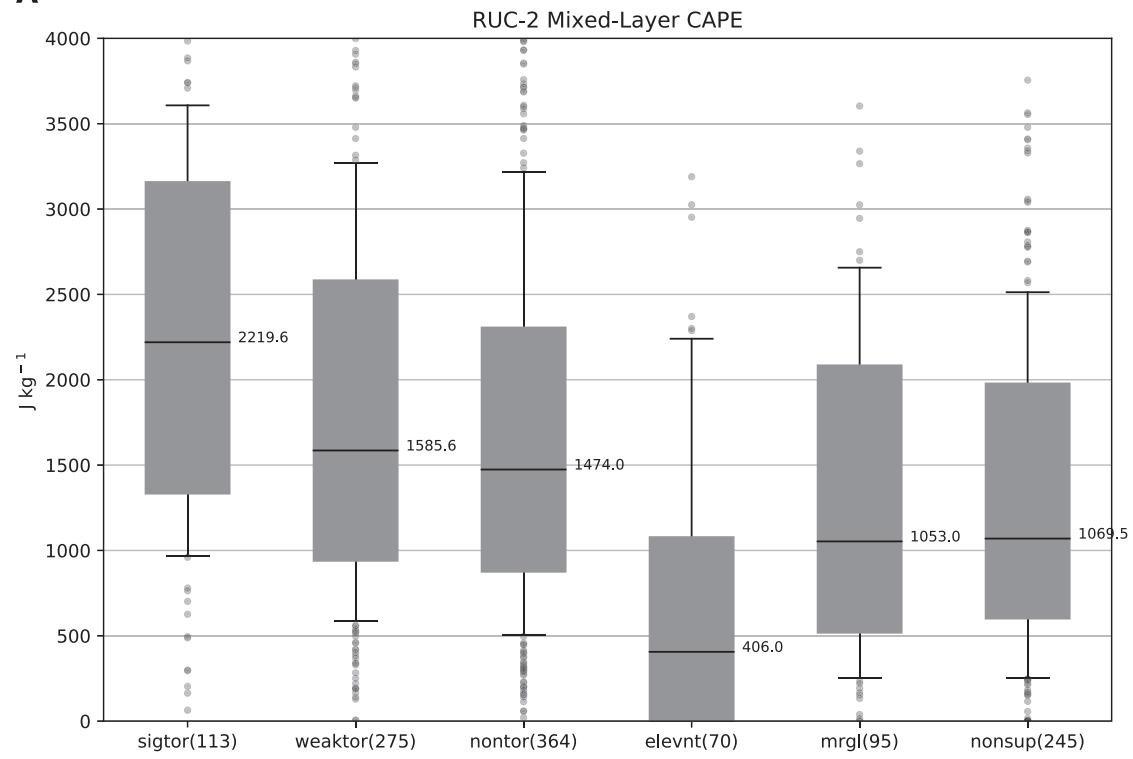

B

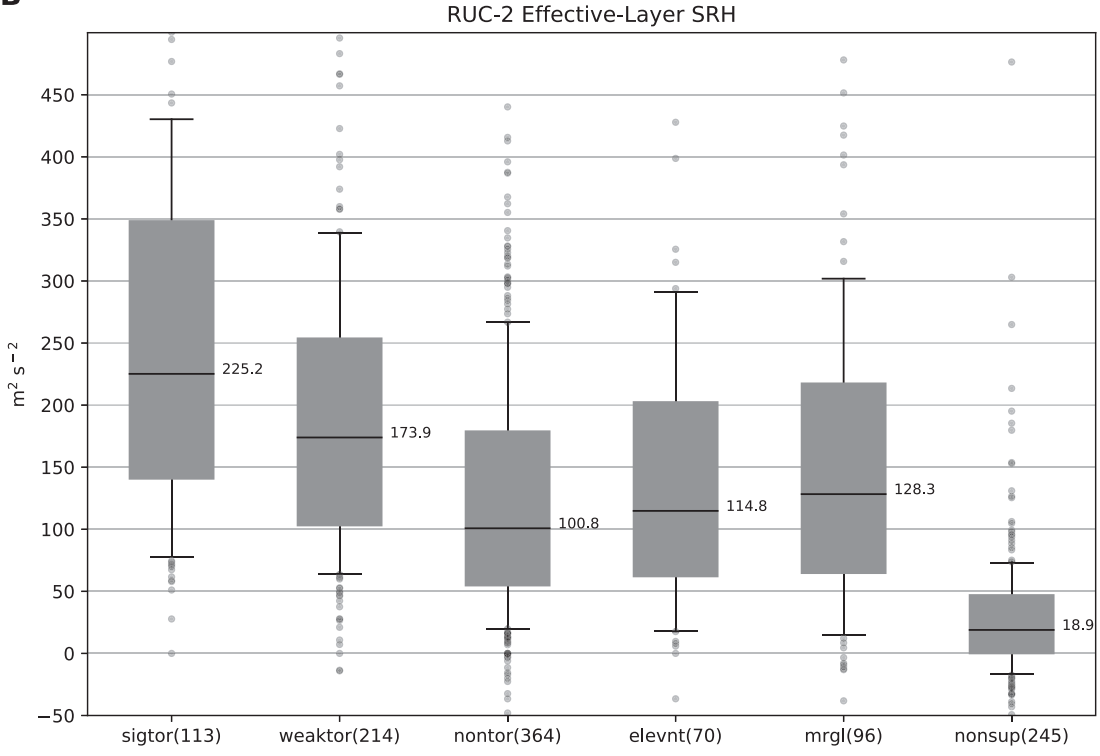

FIG. 1. Box-and-whisker plots of (a) MLCAPE and (b) ESRH for RUC-2 proximity soundings sorted by storm type. Shaded boxes enclose the 25 th-75th percentiles; black lines and printed values represent the medians. Whiskers extend to the lowest and highest values, excluding outliers.

Within the current body of literature, this work will provide proper context to earlier studies that focused on specific reanalyses. Performance of these reanalyses will provide insight into which datasets should be used for future studies to examine the characteristics of severe weather phenomena. If a particular reanalysis is capable of reproducing the results of $\mathrm{T} 03$ and $\mathrm{T} 07$, this may open the door to building a database of proximity soundings to rarer events such as long-track tornadoes that have a notoriously low sample size. It is anticipated that these results will aid climatological studies such as intercomparisons between reanalyses and historical and future climate simulations.

This paper is formatted as follows. Section 2 provides an overview of the datasets used within this study. Section 3 details the process of computing and comparing soundings from the reanalyses and RUC- 2 to evaluate their performance. Statistical results are presented in section 4, and two case studies are provided in section 5. Following a discussion of results in section 6 , a summary of findings and recommendations for future work are found in section 7 . 
A

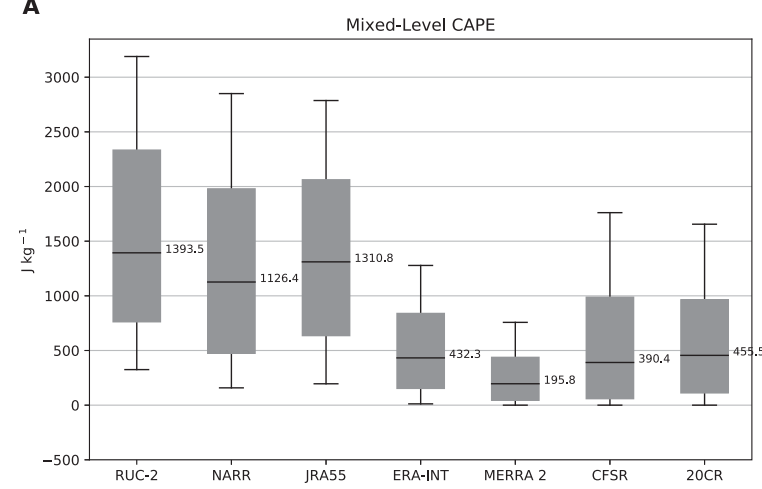

B

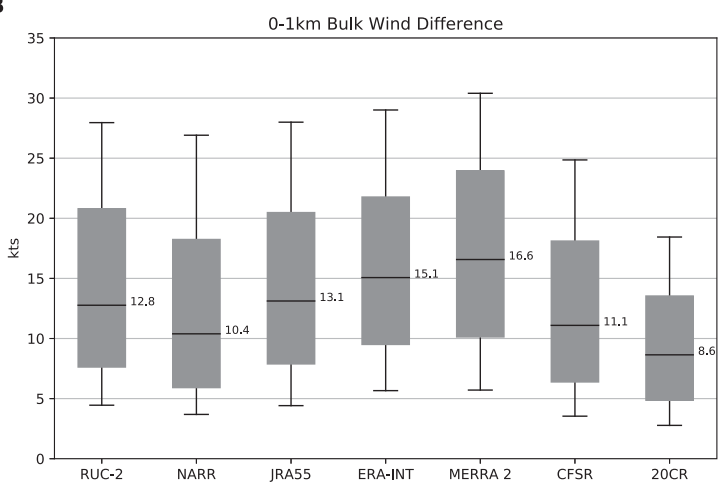

C

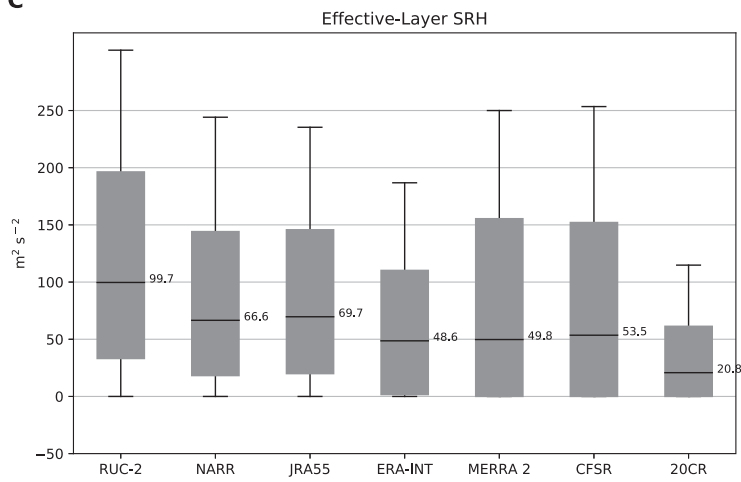

D

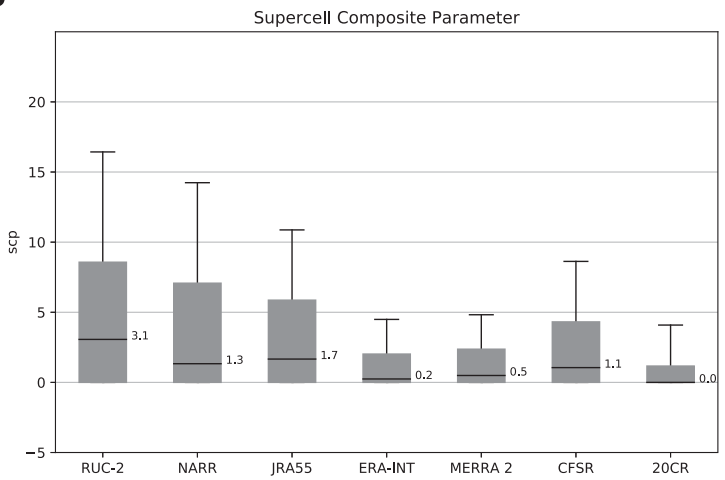

FIG. 2. Similar to Fig. 1, but for (a) MLCAPE, (b) 0-1-km BWD, (c) ESRH, and (d) SCP for RUC-2 and the reanalyses.

\section{Reanalysis datasets}

The reanalyses chosen for analysis included NARR, ERA-Interim, the second generation of MERRA (MERRA-2), the Japanese 55-year Reanalysis (JRA-55), the Twentieth Century Reanalysis (20CR), and CFSR. These datasets represent the latest generation of reanalyses, and as such, older datasets such as NCEP-NCAR and the first generation of MERRA were omitted. Note that the fifth generation of ERA (ERA5) is in production, but data were unavailable for analysis at the time of publication. For brevity, details about these reanalyses are omitted. Rather, the reader is referred to the primary publications that describe these datasets (Table 1).

A unique aspect of reanalyses is the wide number of products generated. Due to space constraints and user purposes, reanalyses are often subset in space and/or time. A good example is NARR, which provides 29 isobaric levels versus the original 45 model layers. For other reanalyses, multiple datastreams may exist. MERRA-2 includes datastreams that have atmospheric variables output in different time intervals, spatial grid spacing, and on different vertical levels (model level vs isobaric). Ideally, proxy soundings should have high temporal, spatial, and vertical resolutions to be most representative of the convective environment. To this end, datastreams were selected that maximized these properties for three-dimensional atmospheric variables. Grid-spacing information along with datastream locations is also provided in Table 1.

\section{Proximity soundings and methods}

Reanalyses were compared with the RUC- 2 proximity soundings from T07. This dataset contains 1185 proximity soundings from predominately supercell environments that are separated into the following five categories:

1) significantly tornadic (F2-F5 tornadoes, denoted as sigtor),

2) weakly tornadic (F0-F1 tornadoes, denoted as weaktor),

3) nontornadic (discrete nontornadic supercells, denoted as nontor),

4) marginal (marginal supercells structure, denoted as $\mathrm{mrgl})$, and

5) nonsupercell (discrete nonsupercells, denoted as nonsuper).

The nontornadic category was further split into surfacebased and elevated storms (denoted as elevnt). This was performed by evaluating the effective inflow layer (T07). If the effective inflow layer was above ground level, the storm was classified as elevated. For categories 1 and 2, "F" refers to the Fujita scale. 


\begin{tabular}{|c|c|c|c|c|c|c|}
\hline Parameters & NARR & ERA-Interim & MERRA 2 & $20 \mathrm{CR}$ & JRA55 & CFSR \\
\hline SBCAPE & 0.66 & 0.60 & 0.64 & 0.56 & 0.64 & 0.36 \\
\hline SBCIN & 0.37 & 0.33 & 0.21 & 0.17 & 0.37 & 0.17 \\
\hline MLCAPE & 0.75 & 0.66 & 0.62 & 0.53 & 0.69 & 0.46 \\
\hline MLCIN & 0.54 & 0.39 & 0.28 & 0.15 & 0.39 & 0.24 \\
\hline MUCAPE & 0.70 & 0.62 & 0.66 & 0.57 & 0.68 & 0.42 \\
\hline MUCIN & 0.38 & 0.25 & 0.33 & 0.19 & 0.34 & 0.23 \\
\hline $\mathrm{SRH}(1 \mathrm{~km})$ & 0.78 & 0.72 & 0.74 & 0.58 & 0.76 & 0.72 \\
\hline $\mathrm{SRH}(3 \mathrm{~km})$ & 0.78 & 0.73 & 0.76 & 0.57 & 0.80 & 0.76 \\
\hline ESRH & 0.66 & 0.55 & 0.63 & 0.46 & 0.65 & 0.60 \\
\hline STP (fixed) & 0.68 & 0.63 & 0.68 & 0.37 & 0.70 & 0.54 \\
\hline SCP & 0.65 & 0.64 & 0.68 & 0.36 & 0.66 & 0.59 \\
\hline STP $(\mathrm{CIN})$ & 0.57 & 0.56 & 0.62 & 0.27 & 0.61 & 0.46 \\
\hline $\operatorname{HEL}(3 \mathrm{~km})$ & 0.68 & 0.67 & 0.68 & 0.63 & 0.71 & 0.65 \\
\hline HEL $(3 \mathrm{~km})$ & 0.79 & 0.73 & 0.75 & 0.68 & 0.79 & 0.77 \\
\hline BWD $(1 \mathrm{~km})$ & 0.66 & 0.60 & 0.64 & 0.56 & 0.64 & 0.36 \\
\hline
\end{tabular}

FIG. 3. Correlation coefficients of popular parameters from the reanalyses with RUC-2. Darker shades represent stronger correlations.

RUC-2 model soundings were chosen in lieu of radiosonde data due to 1) the temporal and spatial availability of the data, 2) the availability of the T07 dataset with discrimination of soundings by storm type, and 3) the performance of RUC-2 in representing the true atmospheric state (T03, Coniglio 2012). The RUC-2 soundings from T07 were compared to each reanalysis via sounding parameters that have been calculated from the proximity soundings (Table 2). While some of these variables (such as CAPE and CIN) are provided by the reanalyses (and were presumably calculated using all model levels), documentation regarding these calculations is sparse. For example, there is no guarantee that all reanalyses used similar parcels (e.g., surface based) or utilized the virtual temperature correction (Doswell and Rasmussen 1994). For example, ERA-Interim uses an approximation for computational efficiency that leads to values of CAPE that are $\sim 20 \%$ higher than those calculated using virtual temperature (ECMWF 2015). In light of this issue, sounding parameters were calculated independently using the Sounding and Hodograph Analysis and Research Program in Python (SHARPpy) software package. This package has been developed to closely emulate methods developed by the SPC that have been rigorously tested (Blumberg et al. 2017).

The proximity soundings for each reanalysis were selected by identifying the nearest grid point to the T07 RUC-2 gridpoint identifiers. Of the original 1187 samples within T07, 22 soundings not associated with METAR locations were unable to be identified and were not used. Two additional soundings did not have parcel traces completed due to erroneous values, and these soundings were also discarded. Once the closest reanalysis grid point was determined, the appropriate reanalysis time step was selected. To understand how temporal variability may impact the analysis as well as to mitigate potential issues with convective contamination or passage of mesoscale features responsible for convective events, times were selected in two different ways:

\begin{tabular}{|l|r|r|r|r|r|r|}
\hline Parameters & NARR & ERA-Interim & MERRA 2 & 20CR & JRA55 & \multicolumn{1}{l|}{ CFSR } \\
\hline SBCAPE & 212.0 & -1021.9 & -1415.6 & -896.8 & -40.6 & -1148.7 \\
\hline SBCIN & 34.9 & 37.1 & 11.5 & 34.6 & 14.8 & -10.7 \\
\hline MLCAPE & -269.6 & -1063.3 & -1305.3 & -955.3 & -184.5 & -942.7 \\
\hline MLCIN & 20.8 & 22.3 & 9.4 & 14.7 & -11.4 & -12.5 \\
\hline MUCAPE & 30.7 & -1196.8 & -1615.6 & -1126.3 & 12.0 & -1179.8 \\
\hline MUCIN & 13.2 & 11.3 & -5.6 & 4.5 & 0.7 & -10.9 \\
\hline SRH $(1 \mathrm{~km})$ & -22.9 & -8.1 & 21.1 & -59.7 & -16.9 & -25.0 \\
\hline SRH $(3 \mathrm{~km})$ & -17.6 & 6.7 & 38.8 & -89.7 & -28.9 & -19.8 \\
\hline ESRH & -31.4 & -59.0 & -40.1 & -89.0 & -35.2 & -40.0 \\
\hline STP $($ fixed $)$ & -0.2 & -0.7 & -0.8 & -0.9 & -0.3 & -0.8 \\
\hline SCP & -1.3 & -4.7 & -5.0 & -5.5 & -2.3 & -3.3 \\
\hline STP $(\mathrm{CIN})$ & -0.3 & -0.7 & -0.8 & -0.9 & -0.4 & -0.7 \\
\hline HEL $(3 \mathrm{~km})$ & -29.9 & -6.6 & 23.3 & -23.8 & -18.5 & -17.0 \\
\hline HEL $(3 \mathrm{~km})$ & -30.9 & -14.4 & 25.5 & -77.0 & -43.5 & -20.4 \\
\hline BWD $(1 \mathrm{~km})$ & -1.6 & 1.5 & 2.8 & -5.1 & -0.00 & -1.0 \\
\hline
\end{tabular}

FIG. 4. As in Fig. 3, but for biases (reanalysis - RUC-2). Redder colors represent positive biases, and bluer colors are for negative biases. 

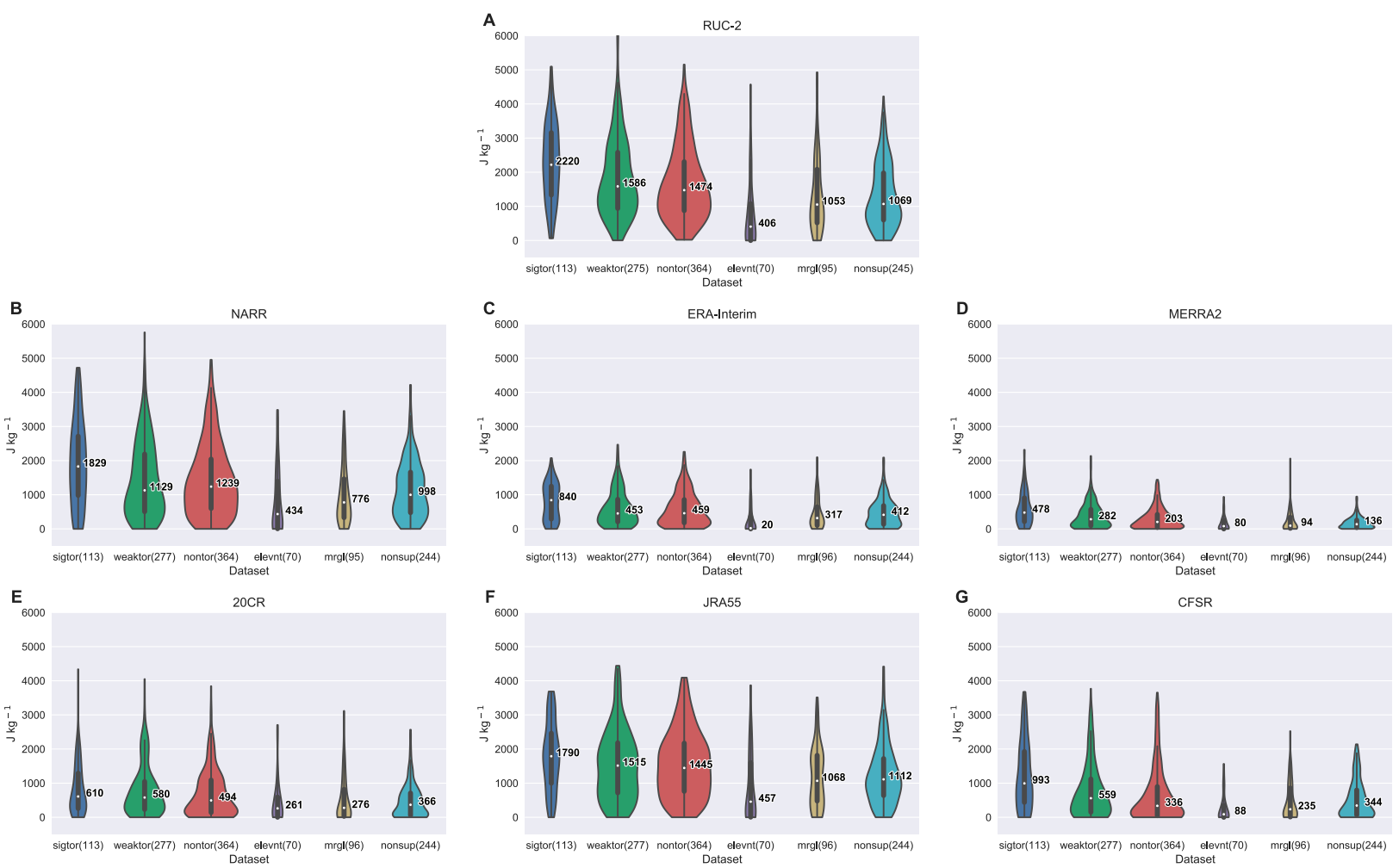

FIG. 5. Violin plots of MLCAPE for (a) RUC-2 and (b)-(g) the reanalyses. Besides displaying traditional box and whiskers with the median values listed, the area is defined by a kernel density function for the distributions. Wider sections of a violin plot represent regions where more members of the distributions reside, and narrower sections contain fewer members. The width of the violins is scaled by the count of values within each bin.

1) closest time to each RUC-2 sounding (e.g., 0000 UTC for a 2300 UTC RUC-2 analysis) or

2) closest time prior to each RUC-2 sounding (e.g., 2100 UTC for the case above).

Once points were selected from each reanalysis, a vertical profile was obtained and required variables (temperature, dewpoint, $u$ component of wind, $v$ component of wind, height, and pressure) were passed to SHARPpy, which performed parcel traces and associated parameter calculations. This process was completed twice for each reanalysis, once while including surface variables (2-m temperature, 2-m dewpoint temperature, 10-m $u$ component of wind, 10-m $v$ component of wind, surface height, and surface pressure), and once by starting from the first model layer. In addition, for those reanalyses that did not utilize a hybrid-sigma pressure coordinate system, checks were performed to ensure that model layers below ground were not used. A list of the sounding parameters calculated from SHARPpy and used in this paper can be found in Table 2. The net result of the process was four different calculations of parameters:

1) closest spatial and temporal point with surface variables,
2) closest spatial and prior temporal point with surface variables,

3) closest spatial and temporal point without surface variables, and

4) closest spatial and prior temporal point without surface variables.

The first calculation (closest in space and time with surface variables) typically yielded the highest correlations with RUC-2 soundings (e.g., 0-1-km BWD correlations of $0.78,0.71,0.76$, and 0.72 for the four methods). As such, results from the first calculation method are presented throughout the paper.

Provided the objectives, SHARPpy was first used to reproduce the RUC- 2 results of T03 and T07. Some differences should be expected between these studies. First, the sample size is slightly different. Second, there are some possible differences in the calculations of sounding parameters between SHARPpy and the Skew- $T$ Hodograph Analysis and Research Program (NSHARP; Hart and Korotky 1991) used in T03 and T07. Although most parameters are nearly identical to NSHARP, those dependent on storm motion (e.g., ESRH) show more variability (Halbert et al. 2015). Furthermore, SHARPpy 

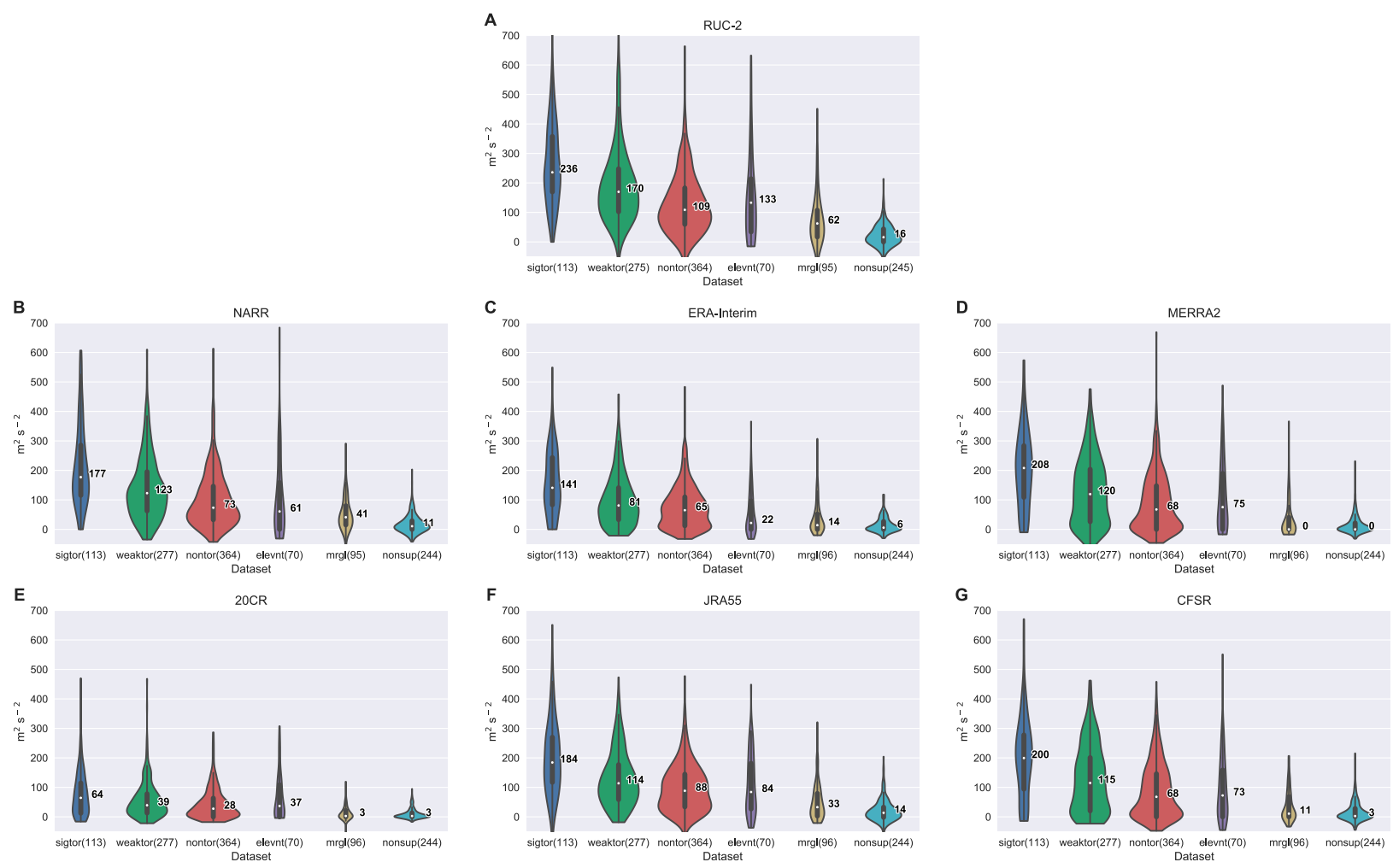

FIG. 6. As in Fig. 5, but for ESRH.

(by default) uses the internal dynamics (ID) method (Bunkers et al. 2000) to calculate storm motion vectors whereas T07 used radar-identified storm centroids. Considering that reanalyses may be used to study historical events that do not have a priori knowledge of storm motion associated with them, SHARPpy-identified storm motion vectors were used and not modified.

By and large, the results are similar to T03 and T07 (Fig. 1). Although the sample size increased from T03 and T07, box-and-whisker plots of MLCAPE look similar to Fig. 6 in T03 (Fig. 1a). MLCAPE decreases from median values of 2220 to $1070 \mathrm{~J} \mathrm{~kg}^{-1}$ from sigtor to nontor supercells. This compares well to the original values of 2152 and $952 \mathrm{~J} \mathrm{~kg}^{-1}$ found in T03. Boxand-whisker plots for effective SRH subject to the parcel constraints of CAPE $\geq 100 \mathrm{~J} \mathrm{~kg}^{-1}$ and CIN $\geq$ $-250 \mathrm{~J} \mathrm{~kg}^{-1}$ are also shown (Fig. 1b; Fig. 8 in T07). Similar to T07, ESRH decreases markedly across the categories with median values decreasing from 225 to $19 \mathrm{~m}^{2} \mathrm{~s}^{-2}$. The largest difference between this study and T07 occurs for the mrgl category. Most likely, storm motion is closer to the mean wind vector versus the vector derived from the ID method (Bunkers et al. 2000). As a result, storms with less deviant motion have reduced ESRH.

\section{Results}

Results are broken down into two sections. In section 4a, statistical properties calculated from all available soundings are presented. In section $4 \mathrm{~b}$, results are segregated by storm type to understand whether the reanalyses can reproduce the results of T07 and T03.

\section{a. Statistical results}

Box-and-whisker plots for the various sounding parameters (Table 2) from each reanalysis are compared with those from RUC-2. For brevity, results are shown for select variables that are more commonly used (Fig. 2). The reanalyses fall into two groups for MLCAPE (Fig. 2a). When compared with the median value of $1394 \mathrm{~J} \mathrm{~kg}^{-1}$ in RUC-2, NARR and JRA-55 have values within $250 \mathrm{~J} \mathrm{~kg}^{-1}$, and the box and whiskers were overlapped. The other reanalyses suffer from a large negative bias, with median values between 196 and $455 \mathrm{~J} \mathrm{~kg}^{-1}$. This narrows the distance between the quartiles, leading to the upper quartile of the reanalyzed distributions falling either below the median (ERA-Interim, CFSR, and 20CR) or lower quartile (MERRA-2) of RUC-2.

Kinematic variables such as 0-1-km BWD (Fig. 2b) and ESRH (Fig. 2c) have smaller dichotomies than MLCAPE. 

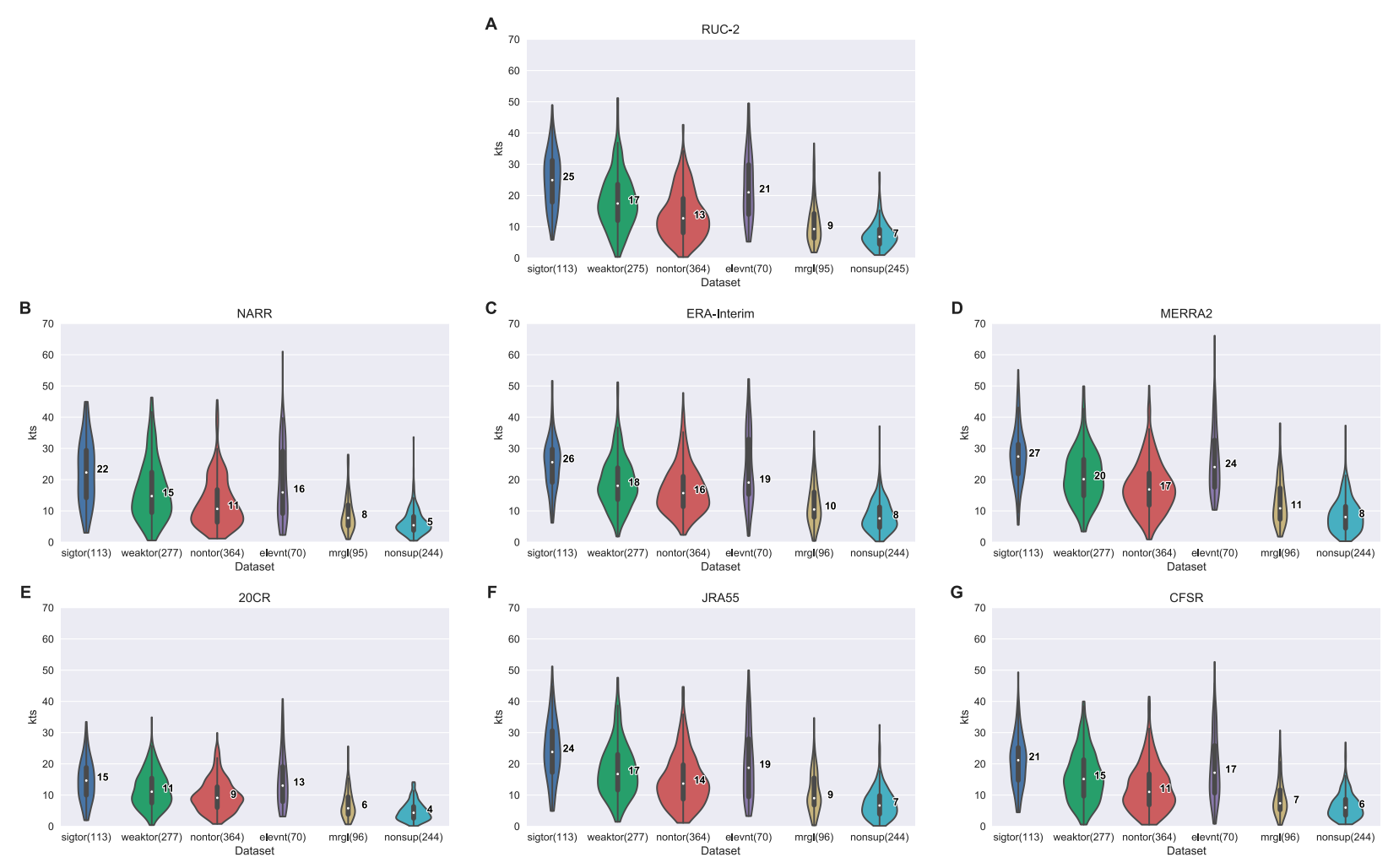

FIG. 7. As in Fig. 5, but for 0-1-km BWD.

In the former case, the reanalysis distributions are similar in width (with the exception of 20CR) with median values within $\pm 4 \mathrm{kt}$ (where $1 \mathrm{kt} \approx 0.51 \mathrm{~m} \mathrm{~s}^{-1}$ ) of the RUC- $2 \mathrm{me}$ dian $(12.8 \mathrm{kt})$. When the effective layer and storm motion vector are considered to calculate ESRH, more separation is found between the reanalyses (Fig. 2c). While all reanalyses have a substantial negative bias relative to RUC-2, the inclusion of thermodynamic information (through the effective layer) causes a separation in the lower quartile for JRA-55 and NARR versus the other reanalyses. Lower CAPE values (regardless of parcel type) observed for ERA-Interim, MERRA-2, CFSR, and 20CR raise the probability that the criteria for inclusion within the effective layer (CAPE $\geq 100 \mathrm{~J} \mathrm{~kg}^{-1}$ and $\mathrm{CIN} \geq \mathrm{J} \mathrm{kg}^{-1}$ ) are not met. This results in a narrower effective layer, lowering the values of ESRH. Given that SCP is also a function of CAPE, this property also significantly decreases the median and upper quartiles of this parameter (Fig. 2d).

To provide a concise way to evaluate the ability of the reanalyses to reproduce RUC-2 calculated parameters, Pearson correlation coefficients and biases (reanalysis RUC-2) were calculated (Figs. 3 and 4). Higher correlations imply a stronger linear relationship between datasets. Scatterplots (not shown) suggested that linear relationships were adequate to grossly understand the agreement between the reanalyses and RUC-2. These correlations reinforce the notion that reanalyses are more likely to have issues with the thermodynamic properties of the soundings. Although moderate-tostrong correlations are found for CAPE depending on the type of parcel trace (SB, ML, and MU), all reanalyses struggle with CIN regardless of how it is calculated. NARR, for example, has a maximum correlation of 0.54 for MLCIN with the other reanalyses lagging further behind (e.g., 0.39 for ERAInterim and JRA-55). Biases for the reanalyses are generally negative for CAPE and positive for CIN. Exceptions to this rule include SBCAPE for NARR, ML and MUCIN for JRA-55, and all CIN values for CFSR. Although surface-based parcels generally increase the CAPE and yield lower biases, this is at the expense of lower correlations. In most cases, this difference (e.g., 0.66 vs 0.75 for NARR) is statistically significant.

Reanalyses perform more consistently for kinematic variables such as fixed-level SRH and BWD (Fig. 3). Excluding 20CR, correlations for SRH range between 0.72 and 0.80 . While the reanalyses are biased low for SRH and helicity (with the exception of MERRA-2; Fig. 4), the strong correlations suggest that the reanalyses do a better job simulating the wind field versus the thermodynamic profile. That said, given the strong dependence of storm type on low-level helicity 

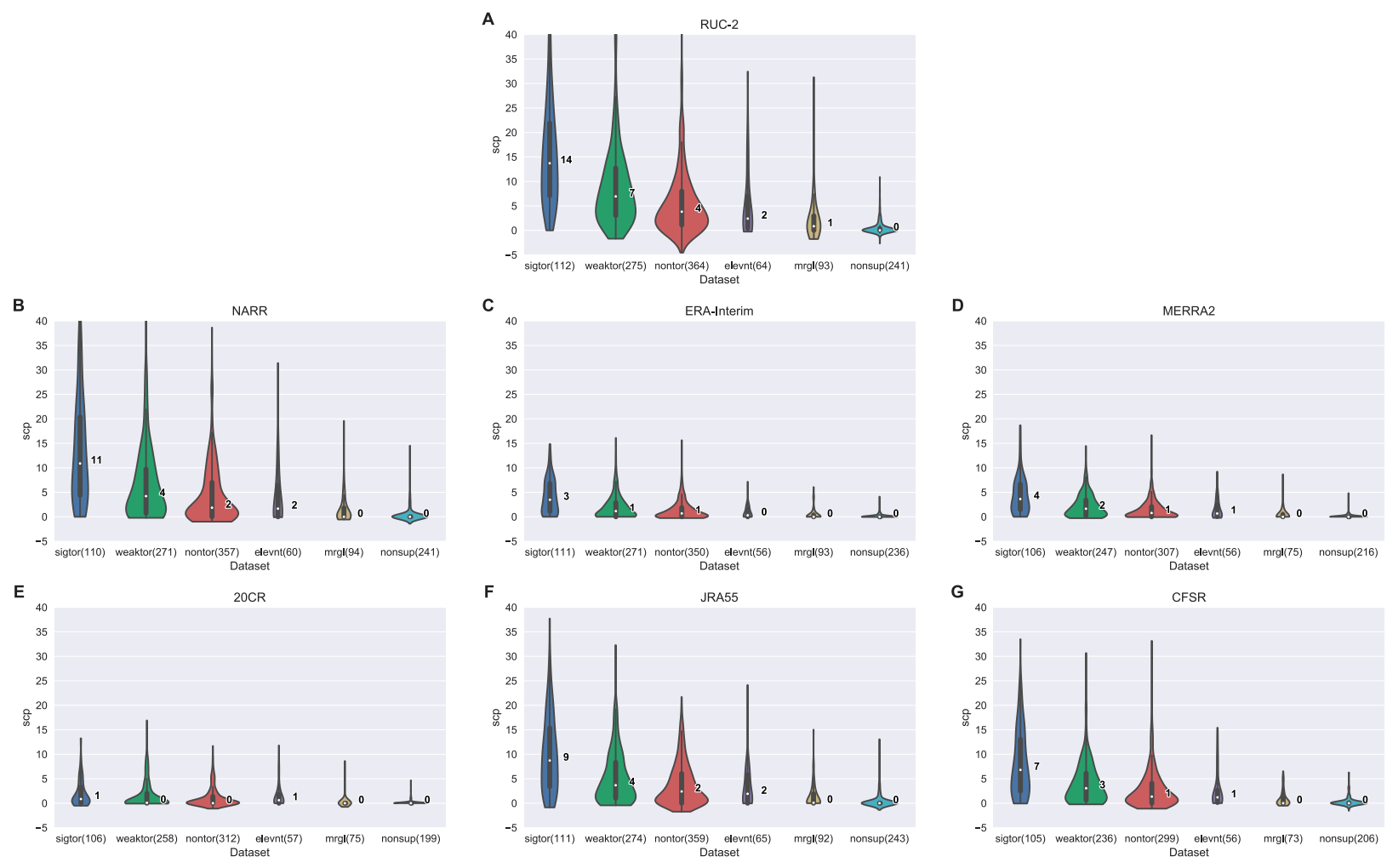

FIG. 8. As in Fig. 5, but for SCP.

(T07), low biases may mean it is more difficult to segregate between categories.

The final category of parameters is those that mix thermodynamic and kinematic properties. Relative to straight kinematic parameters, the inclusion of thermodynamic information leads to decreases in correlations (e.g., 0-1-km SRH vs ESRH; Fig. 3). Considering parameters that are a combination of CAPE and shear (e.g., SCP and STP), biases are largely controlled by the thermodynamic characteristics for a reanalysis. NARR and JRA-55, which have higher CAPE values, contain the smallest biases for these parameters, whereas the other reanalyses are impacted by the low values of CAPE.

\section{b. Comparison of reanalyses with T03 and T07}

Prior to presenting the results, the methods for discriminating between environments must be defined. Similar to Reames (2017), significant discriminators are defined as those in which the median of a defined distribution is below the lower quartile or above the upper quartile of another. To put T03 and T07 in context of this criterion, the following parameters are good discriminators between categories:

- MLCAPE—sigtor, elevnt, and mrgl/nonsup;
- 0-1-km BWD—sigtor, weaktor and nontor, and $\mathrm{mrgl} /$ nonsup;

- ESRH—sigtor, nontor, and nonsup;

- SCP-sigtor, nontor, and $\mathrm{mrgl} / \mathrm{nonsup}$; and

- STP-sigtor, weaktor/nontor.

To visualize both the quartiles and probability density functions for the various categories, violin plots are shown for select parameters (Figs. 5-9).

MLCAPE distributions in RUC-2 demonstrate a general decrease and broadening of MLCAPE as categories make the transition from sigtor to weaktor and then to nontor (Fig. 5a). Although sigtor, elevnt, and margl/nonsup meet the criteria for being a good discriminator, significant overlap is still found among the categories. For the reanalyses, a quick comparison of median values demonstrates the same trend in magnitude, but with substantially more overlap. Of the presented datasets, only NARR (Fig. 5b) and CFSR (Fig. 5g) successfully discriminate between some of the categories (sigtor and mrgl). While JRA-55 has MLCAPE on the same order of magnitude as NARR and RUC-2, inspection of the individual categories reveals a negative bias for sigtor offset via higher values for the other categories. This leads to additional overlap between the distributions, and no discrimination. For 


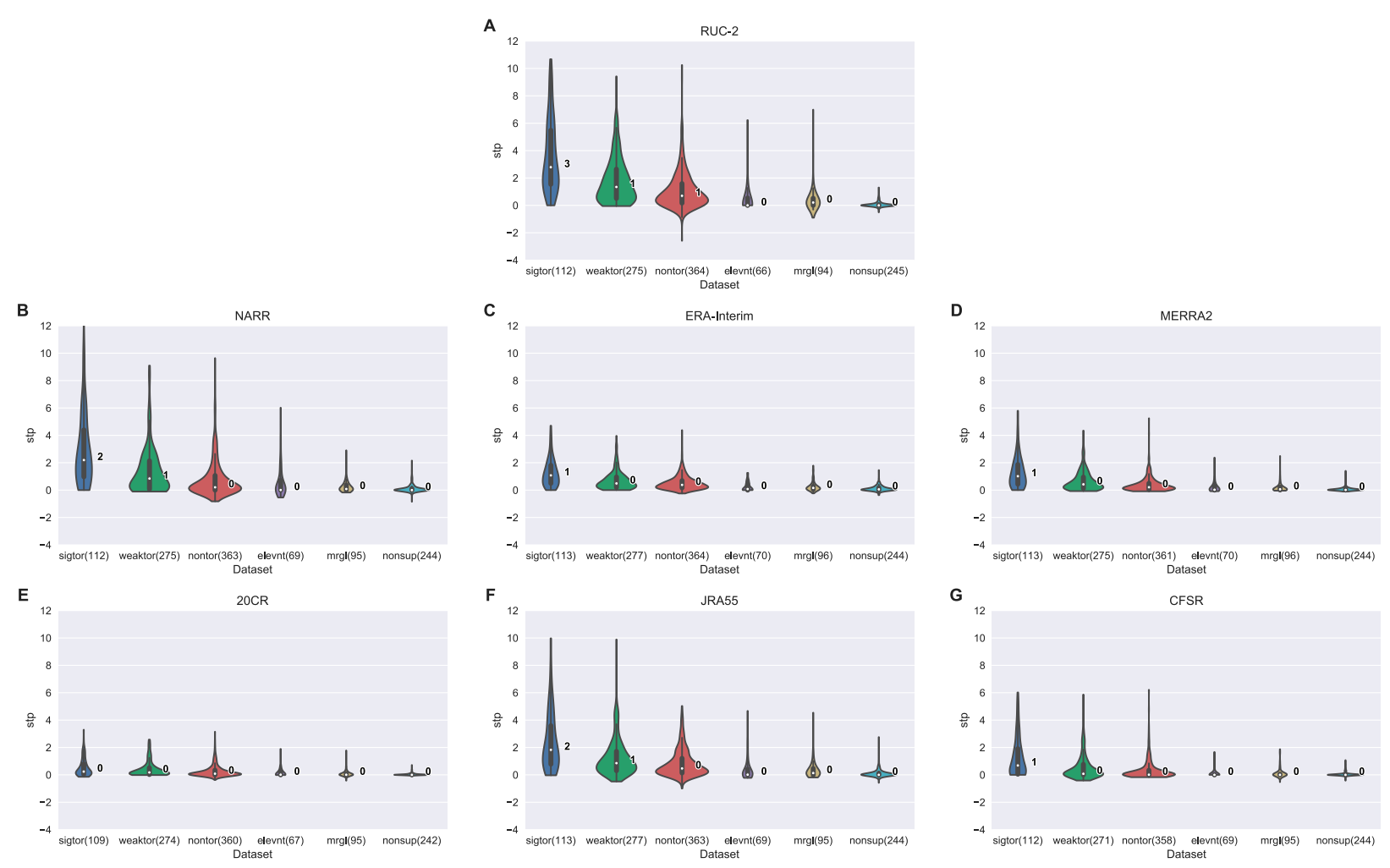

FIG. 9. As in Fig. 5, but for STP.

the other reanalyses, large negative biases for MLCAPE narrow the distributions, making discrimination impossible.

As demonstrated by Fig. 6, ESRH is a reasonable discriminator between tornadic and nontornadic events for RUC-2 soundings in T07. Compared to MLCAPE, comparisons between the reanalyses and RUC-2 are much better. Qualitatively, the shapes of the violins are similar with a decrease and broadening of the distributions as storm type shifts from sigtor to nonsup. As a result, all of the reanalyses except 20CR (Fig. 6e) discriminate between the sigtor and nontor categories. The predominant issue with 20CR is an overall negative bias in ESRH across all categories. Whereas RUC-2 and the other reanalyses have a probability maximum located between 150 and $250 \mathrm{~m}^{2} \mathrm{~s}^{-2}, 20 \mathrm{CR}$ is located at $\sim 25 \mathrm{~m}^{2} \mathrm{~s}^{-2}$.

A better kinematic discriminator for these environments in reanalyses is $0-1-\mathrm{km}$ BWD (Fig. 7). While RUC-2 discriminates between categories in a similar fashion between this parameter and ESRH, more separation is found between categories for the reanalyses. Even 20CR, which has the largest negative bias for kinematic parameters, has significant separation between categories (Fig. 7e).

To discriminate between environments supportive of long-lived, rotating updrafts, SCP is used (T03). Values $>1$ are strongly supportive of supercells as noted by the differences between the nontor and $\mathrm{mrgl} / \mathrm{nonsup}$ categories in RUC-2 (Fig. 8a). Because SCP is a product of kinematic and thermodynamic parameters, performance is affected by biases in CAPE. While the distributions in reanalyses are concentrated on a value of 0 for the mrgl and nonsup categories, SCP values for stronger categories are biased low. As a result, this makes discrimination of the supercell and nonsupercell categories difficult. Even for reanalyses like NARR (Fig. 8b) and JRA-55 (Fig. 8f) that have reasonable performance for MLCAPE, formal discrimination is limited to nonsupercell categories versus strongly and weakly tornadic storms. CFSR (Fig. 8g) is also capable of making this distinction, while ERA-Interim (Fig. 8c) and MERRA-2 (Fig. 8d) can only distinguish between sigtor and the nonsupercell categories.

STP is used to distinguish between strongly tornadic and nontornadic supercell environments with values $>1$, maximizing forecast skill between these categories (T03). SHARPpy provides two styles of this parameter: one based on the effective inflow layer, and the other with a fixed layer. From prior discussion (ESRH vs 0-1-km BWD), the fixed-layer STP is shown in Fig. 9 and discussed herein. As shown in T03 and Fig. 9a, RUC-2 sigtor can be discriminated from all other categories because the median of weaktor (0.85) is lower than the lower 
B

$\mathbf{E}$

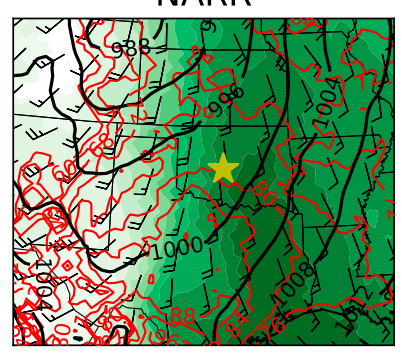

$20 C R$

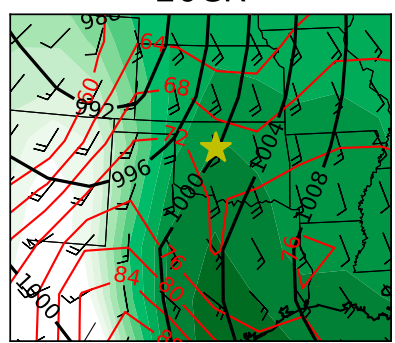

A

RUC-2

C

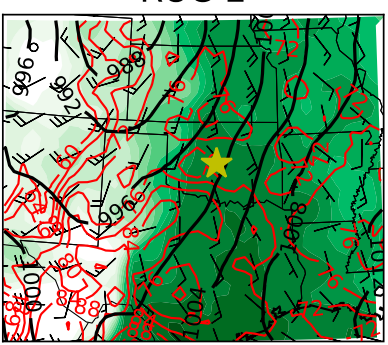

ERA-Interim

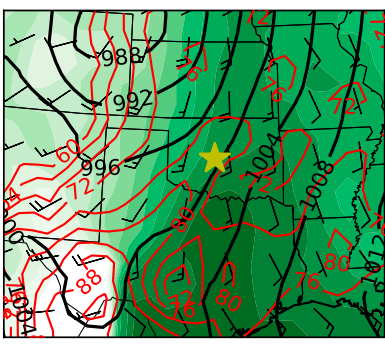

$\mathbf{F}$

JRA55

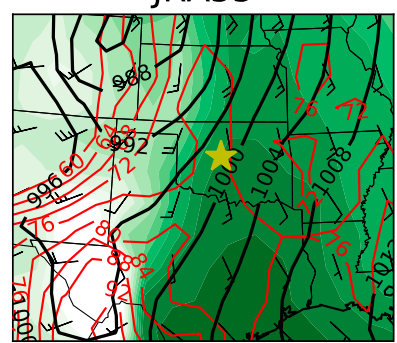

MERRA 2

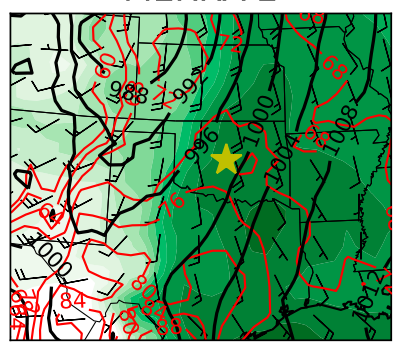

G

CFSR

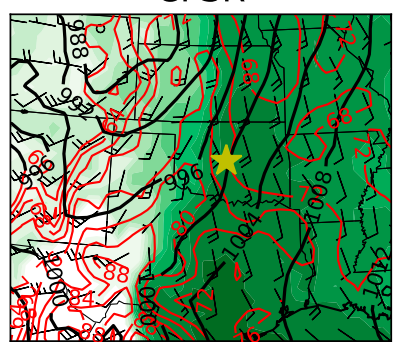

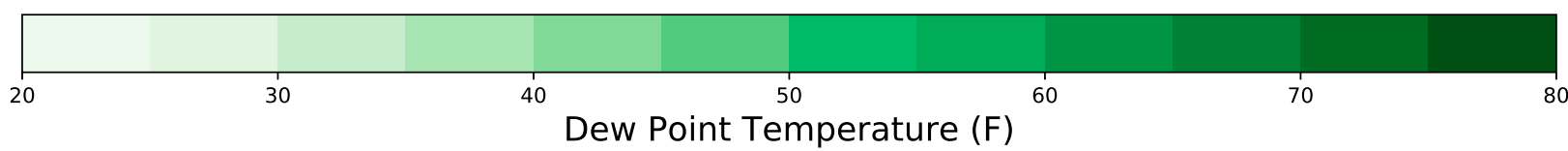

FIG. 10. Surface analyses for (a) RUC-2 at 2300 UTC 3 May 1999 and (b)-(g) reanalyses at 0000 UTC 4 May 1999. Dewpoint temperatures are shaded, and MSLP and temperatures are contoured with black and red lines, respectively. For the sake of clarity, select wind barbs are plotted by subsampling each reanalysis to achieve points $\sim 120-200 \mathrm{~km}$ distant from each other. For example, every fourth grid point is plotted for NARR. Yellow stars represent the locations for soundings shown in Fig. 12, below.

quartile of sigtor (0.97). Although STP is lower for all reanalyses, NARR (Fig. 9b), ERA-Interim (Fig. 9c), and MERRA-2 (Fig. 9d) successfully discriminate between the sigtor and weaktor categories. That said, the distance between the lower quartile of sigtor and the median of weaktor is much narrower than RUC-2, and more overlap occurs. JRA-55 (Fig. 9f) and CFSR (Fig. 9g) have more overlap but can discriminate between sigtor and nontor categories. The 20CR has the worst overlap, and discrimination can only occur between sigtor and $\mathrm{mrgl} /$ nonsup cases.

\section{Example cases}

To put statistical results into context and to demonstrate how reanalyses depict tornadic environments, two example cases were chosen from T07: 3 May 1999 [Oklahoma City, Oklahoma (OKC)] and 18 July 2004 [Grand Forks, North Dakota (GFK)]. These events were selected on the basis of varying meteorological environments, scales of impact, and previous discussion in the literature.

\section{a. 3 May 1999 OKC}

The Oklahoma (OK) event on 3 May 1999 was a significant severe weather outbreak that generated 69 tornadoes from 10 distinct supercell thunderstorms. Given that the primary purpose in this paper is to compare the suite of reanalyses with RUC-2, a full discussion of this event is not included. Rather, the reader is referred to Thompson and Edwards (2000), who provide an excellent overview of the complex 


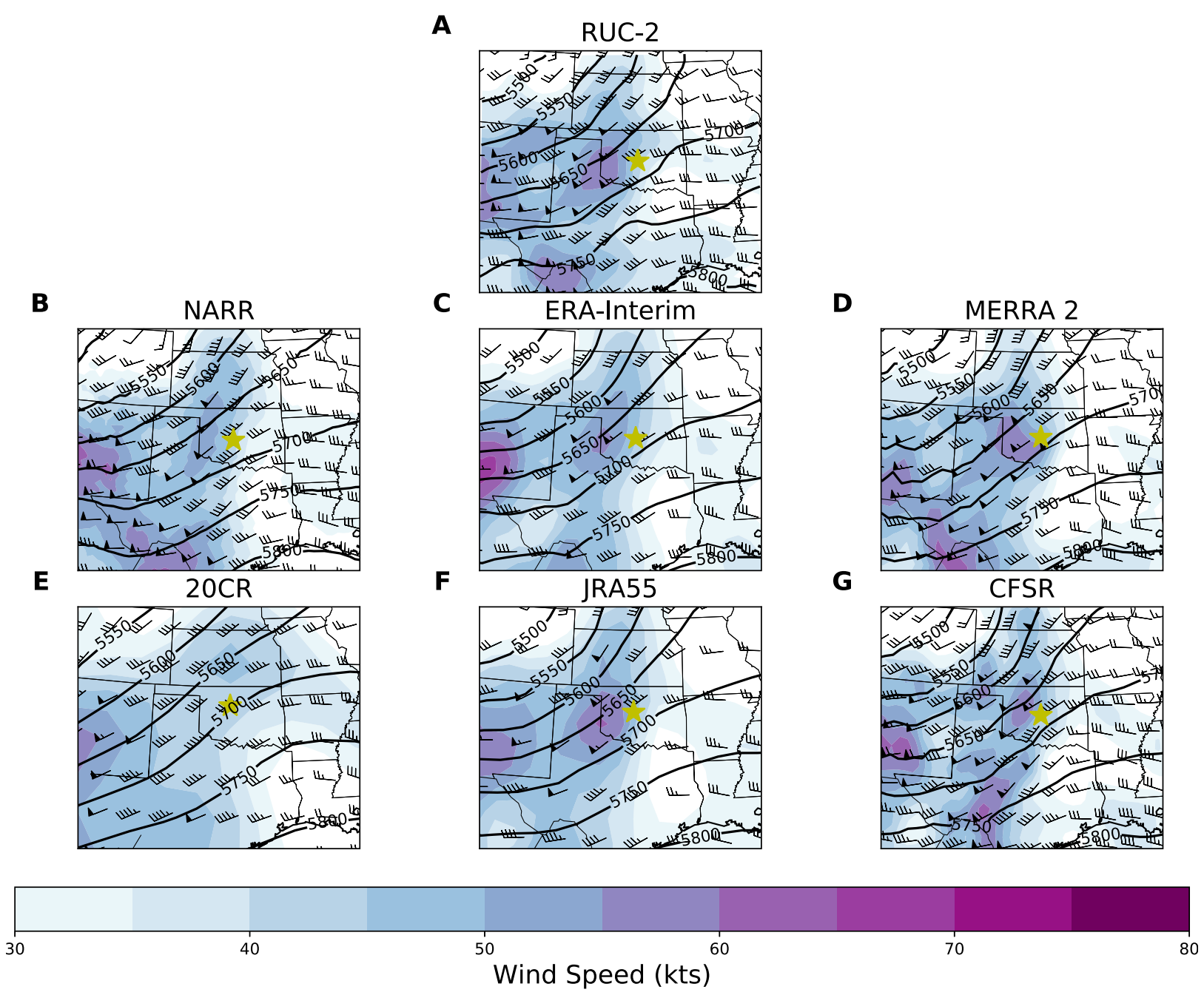

FIG. 11. As in Fig. 10, but for 500-hPa analyses. Wind magnitudes are shaded, and geopotential heights are contoured with black lines.

surface and upper-level features that contributed to this tornado outbreak. Besides this paper, Burgess et al. (2002) detailed a radar-based discussion of the event using WSR-88D and Doppler on Wheels. Additional information on the event can be found in Markowski (2002), Roebber et al. (2002), and Stensrud and Weiss (2002).

Surface analyses for this event at $\sim 0000$ UTC 4 May 1999 are provided in Fig. 10. The surface cyclone centered over northeastern Colorado and western Nebraska, a broad region of lee troughing with low-level advection of moisture, and a dryline are apparent in all of the reanalyses. There are a few notable differences from the RUC-2 (Fig. 10a). The extent of moisture and values of dewpoints varied across the warm sector $\left[70^{\circ}-\right.$ $77^{\circ} \mathrm{F}\left(21^{\circ}-25^{\circ} \mathrm{C}\right)$ at $\left.\mathrm{OKC}\right]$. Many of the reanalyses had a more diffuse dryline, while the 20CR (Fig. 10e) had a weaker, northerly displaced cyclone. Many of these properties are expected because of the reduced spatial and temporal resolution of the reanalyses and, in the case of 20CR, the ensemble nature of this reanalysis.

Upper-air patterns at $500 \mathrm{hPa}$ for this event are depicted in Fig. 11. Like many outbreaks, this event was associated with a short-wave trough and an $\sim 50$-kt jet streak embedded within larger-scale southwesterly flow. While the jet was present in the reanalyses, there were some subtle differences in both the positioning and magnitude of the jet between RUC-2 (Fig. 11a) and the reanalyses (Figs. 11b-g). Using the 50-kt isopleth as a guideline, 20CR (Fig. 11e) has the poorest representation of the event because the jet maximum over western Oklahoma apparent in RUC-2 and other reanalyses was absent. Other differences include a slight negative (low) bias in NARR (Fig. 11b) for the local maxima just west of $\mathrm{OKC}$, and a lack of higher-magnitude winds over southern Texas in JRA-55 (Fig. 11f). Radiosonde data 
A

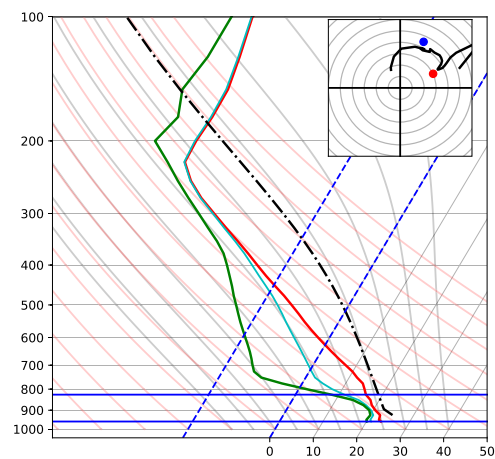

B

NARR

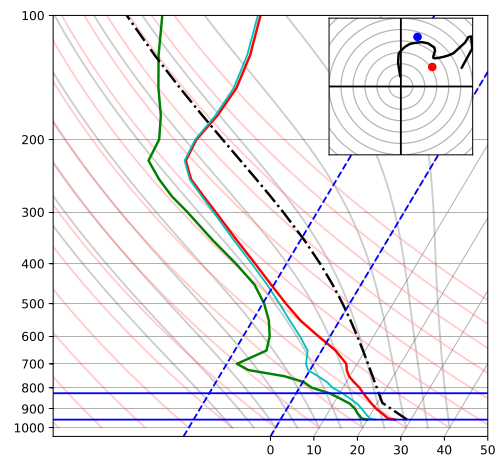

$\mathbf{E}$

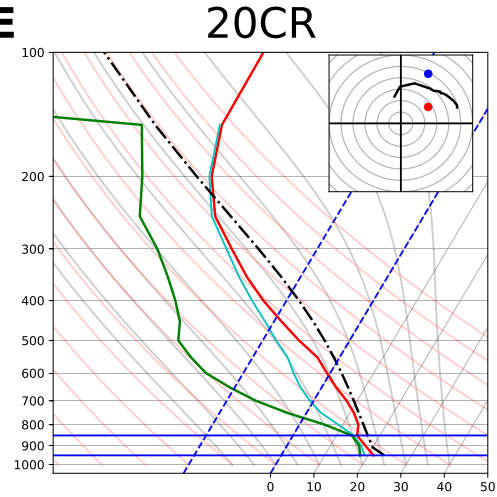

C

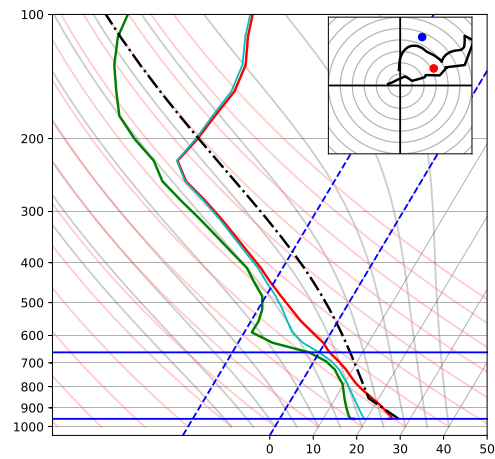

$\mathbf{F}$

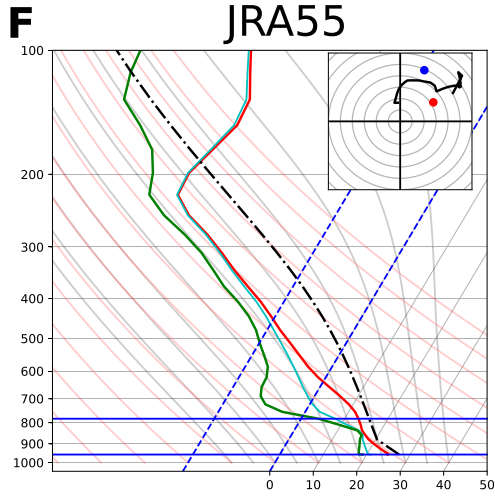

D MERRA 2

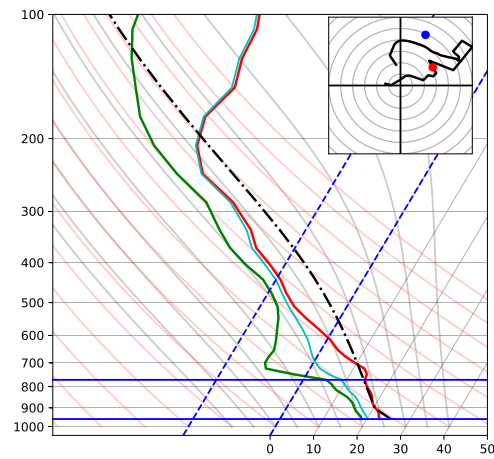

G

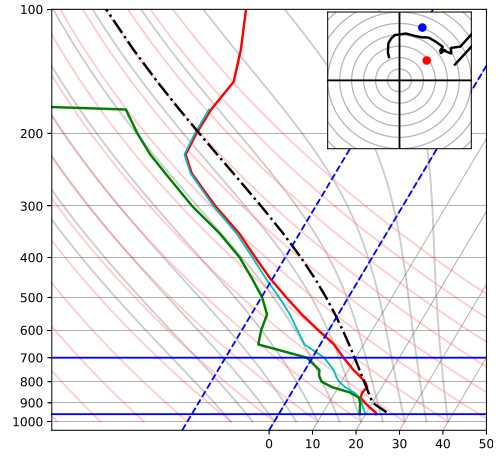

FIG. 12. Proximity soundings near OKC for (a) RUC-2 at 2300 UTC 3 May 1999 and (b)-(g) reanalyses at 0000 UTC 4 May 1999. Locations are marked by the yellow stars in Figs. 10 and 11. Bunker's storm-motion right mover and left mover are indicated as red and blue dots, respectively, within each inset hodograph.

from this time included 65-, 45-, and 50-55-kt observations over southern Texas, the Texas panhandle, and New Mexico, respectively. This suggests that, relative to observations, NARR may have had the best agreement in light of possible observation errors.

To understand the vertical structure of the environment, soundings for this event are shown in Fig. 12, with the convective parameters listed in Table 3. Variations in lapse rates, depths of moist and dry layers, effective inflow layers, hodographs, and surface temperaturedewpoint spreads are apparent in the reanalyses, and these factors contribute to a spread of values in the derived parameters. Even the RUC-2 sounding from 2300 UTC 3 May 1999 at OKC (Fig. 12a) has noticeable differences with the 0000 UTC sounding on 4 May 1999 at Norman, Oklahoma (OUN) (Fig. 13). Given the proximity to ongoing convection, this result should not be surprising.

Calculations of CAPE varied across the datasets. Observed and RUC-2 analyzed MLCAPE (SBCAPE) for this case were 2886 (3222) and 4199 (3891) $\mathrm{J} \mathrm{kg}^{-1}$, respectively. Much like the statistical results, the reanalysis-calculated CAPE fell into two camps with JRA-55, NARR, and CFSR producing reasonable 
TABLE 3. Select sounding parameters for the 3 May 1999 case. Parameters correspond to the soundings shown in Figs. 12 and 13.

\begin{tabular}{|c|c|c|c|c|c|c|c|c|}
\hline \multirow[b]{2}{*}{ Sounding } & \multirow[b]{2}{*}{$\operatorname{MLCAPE}\left(\mathrm{J} \mathrm{kg}^{-1}\right)$} & \multirow[b]{2}{*}{$\operatorname{SBCAPE}\left(\mathrm{J} \mathrm{kg}^{-1}\right)$} & \multirow[b]{2}{*}{$\operatorname{SBLCL}(\mathrm{m})$} & \multicolumn{2}{|c|}{$\mathrm{SRH}\left(\mathrm{m}^{2} \mathrm{~s}^{-2}\right)$} & \multicolumn{2}{|c|}{ BWD (kt) } & \multirow[b]{2}{*}{$\mathrm{SCP}$} \\
\hline & & & & $0-1 \mathrm{~km}$ & Effective & $0-1 \mathrm{~km}$ & Effective & \\
\hline OUN & 2886 & 3222 & 423 & 254 & 278 & 25 & 27 & 17.9 \\
\hline RUC-2 & 4119 & 3891 & 417 & 309 & 298 & 32 & 30 & 28.1 \\
\hline NARR & 3142 & 4819 & 808 & 235 & 249 & 28 & 29 & 24.1 \\
\hline ERA-Interim & 1413 & 1614 & 558 & 235 & 263 & 27 & 32 & 8.5 \\
\hline MERRA-2 & 978 & 1149 & 371 & 310 & 314 & 27 & 28 & 7.2 \\
\hline 20CR (V2) & 1541 & 1682 & 390 & 155 & 151 & 21 & 20 & 5.1 \\
\hline JRA-55 & 3681 & 4087 & 750 & 187 & 253 & 21 & 28 & 20.8 \\
\hline CFSR & 2950 & 2960 & 473 & 234 & 383 & 23 & 41 & 23 \\
\hline
\end{tabular}

estimates (3681-2950 $\mathrm{J} \mathrm{kg}^{-1}$ for MLCAPE) while 20CR, ERA-Interim, and MERRA-2 grossly underreanalyzed this variable $\left(1413-978 \mathrm{~J} \mathrm{~kg}^{-1}\right)$. The reasons for these differences are varied, but some of the more obvious factors include a negative (dry) bias in the boundary layer for ERA-Interim (Fig. 12c) and warmer midlevel temperatures for MERRA-2 (Fig. 12d). While NARR (Fig. 12b) and JRA-55 (Fig. 12f) had the highest values of MLCAPE and an effective inflow layer that was similar to that of RUC-2, the higher values of CAPE can be attributed in part to a positive (warm) bias at the surface. This property led to higher lifted condensation level (LCL) heights than were observed (Table 3).

Kinematic parameters also demonstrated a range in results. Variables such as SRH (effective or absolute height) were lower than observed for most of the reanalyses. For example, $0-1-\mathrm{km} \mathrm{SRH}$ values in the

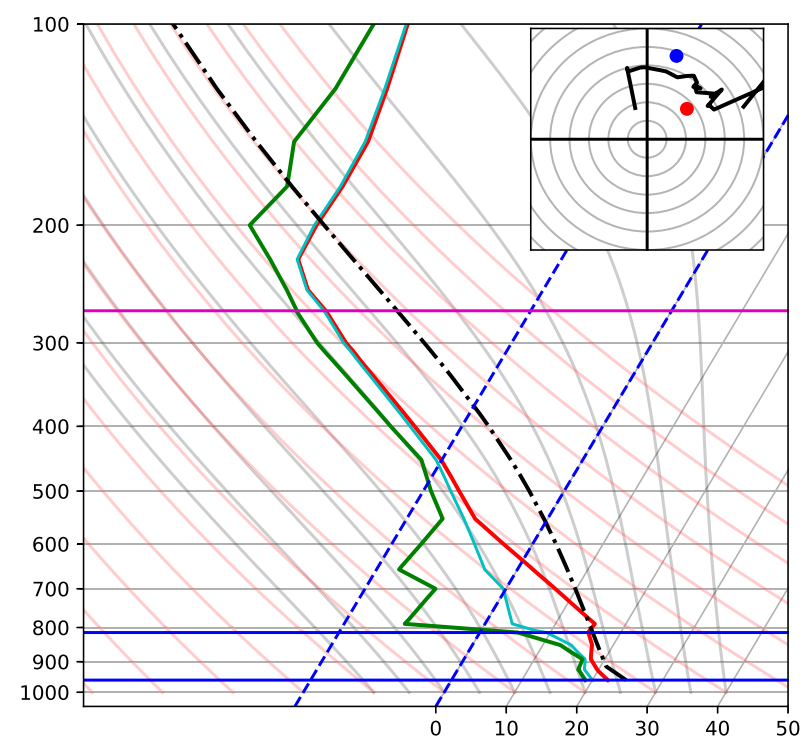

FIG. 13. Observed sounding from OUN at 0000 UTC 4 May 1999. Because the observed OUN sounding ended early ( $\sim 275 \mathrm{hPa}$; magenta line), the sounding was augmented with the RUC-2 proximity sounding above this level to allow calculation of CAPE. reanalyses ranged from 155 to $310 \mathrm{~m}^{2} \mathrm{~s}^{-2}$ as compared with the observations at OUN and the RUC-2-analyzed values of 255 and $309 \mathrm{~m}^{2} \mathrm{~s}^{-2}$, respectively (Table 3). Of these reanalyzed values, only MERRA-2 (Fig. 12d; $310 \mathrm{~m}^{2} \mathrm{~s}^{-2}$ ) fell near this range, and this reanalysis was consistently higher than RUC- 2 or OUN. Interestingly, this reanalysis along with $20 \mathrm{CR}$ had the poorest representations of the sickle-shaped hodograph that was seen in most of the soundings. Although CFSR (Fig. 12g) had a $0-1-\mathrm{km}$ SRH that was lower than observed (because of lower 0-1-km BWD), the effective and 0-3-km SRH values were also higher than RUC-2 and OUN. For ESRH, this is most likely related to an effective layer that was deeper than observed. Other than these two examples, the remainder of the reanalyses (NARR, JRA-55, ERA-Interim, and 20CR) were lower than RUC-2 and OUN for SRH. Despite this issue, these reanalyses were within a few knots of the effective BWD (EBWD), with the exception of 20CR (Fig. 12e, Table 3).

\section{b. 18 July 2004 GFK}

The second case study was a more isolated severe weather event in eastern North Dakota (ND) that produced several tornadoes, one of which was an F4. Kellenbenz et al. (2007, hereinafter KGD07) examined this northwest-flow event and hypothesized that evapotranspiration processes were responsible for enhancing boundary layer moisture. While KGD07 stressed the high ML LCL heights $(\sim 1800 \mathrm{~m})$, Edwards and Thompson (2009) pointed out that, while corrected values $(\sim 1400 \mathrm{~m})$ were high, they still fell within upper percentile ranges for multiple studies (e.g., T03). Edwards and Thompson (2009) also provided other additional details and corrections to the study by KGD07. Regardless of these issues, this is a reasonable case to explore because of the larger dewpoint depressions and weaker shear relative to 3 May 1999.

Surface analyses for 0000 UTC 19 July 2004 are provided in Fig. 14. Unfortunately, RUC-2 analyses were 
A

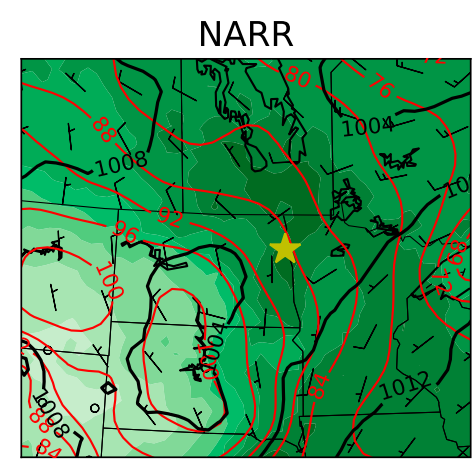

D

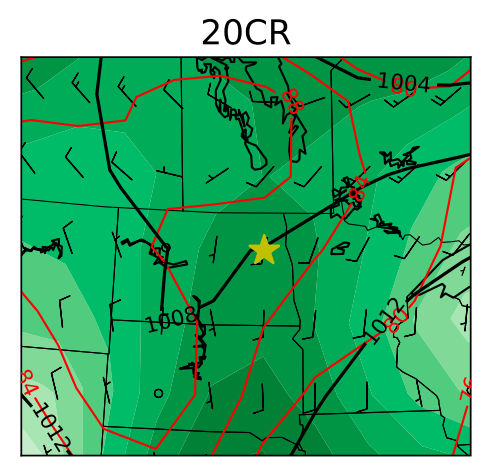

B

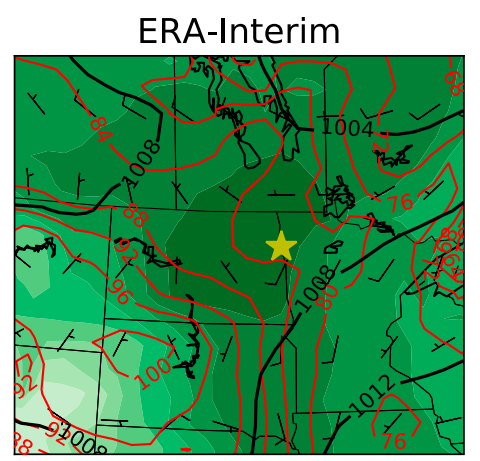

$\mathbf{E}$

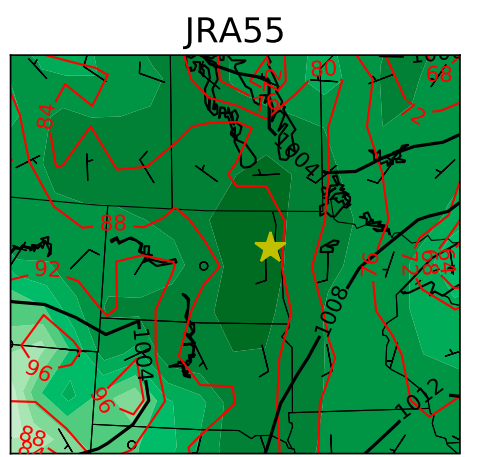

C

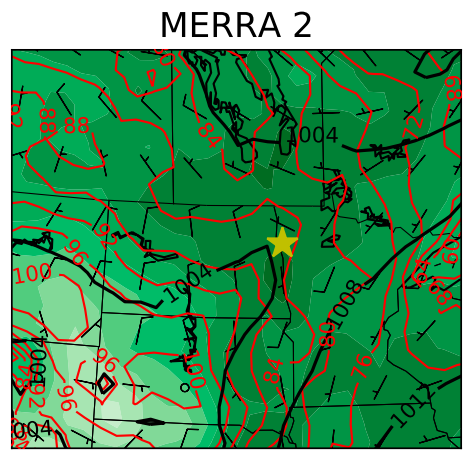

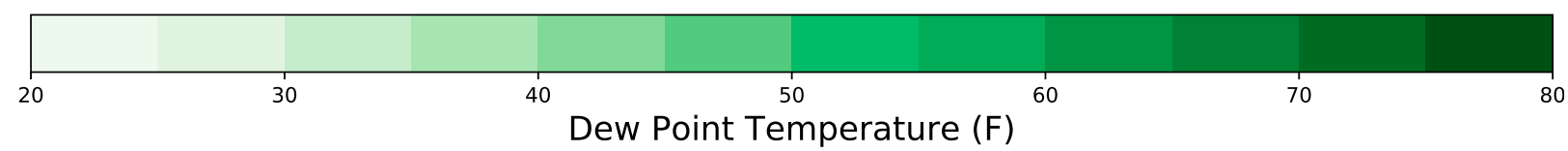

FIG. 14. The 0000 UTC 19 Jul 2004 surface analyses for the reanalyses. Contoured variables are as in Fig. 10.

unavailable for this case. Instead, comparisons are made with the surface analysis shown in Fig. 14 of KGD07. Pertinent features from this figure included a surface pressure trough oriented from southwest to northeast across the region and surface temperatures and dewpoints around $83^{\circ}-89^{\circ} \mathrm{F}$ and $70^{\circ}-73^{\circ} \mathrm{F}$, respectively. While the wind shift is seen in many of the reanalyses, the trough was much harder to discern. Furthermore, the reanalyses had varying biases for the surface thermodynamic fields. Although most of the reanalyses and the surface analysis had a moist axis in eastern ND, surface dewpoints were too dry $\left(\sim 0^{\circ}-3^{\circ} \mathrm{F}\right)$. The reanalyses also showed evidence of a thermal ridge that was oriented with the surface trough, but the position varied, and this led to varying biases across the domain. NARR (Fig. 14a) had perhaps the most notable issue with surface temperatures, with values $5^{\circ}-10^{\circ} \mathrm{F}$ too high across the domain. Gradients were too weak in $20 \mathrm{CR}$ (Fig. 14d), and the wind shift was displaced well north of the observed location. Subjectively, ERA-Interim (Fig. 14b) appeared to have the best representation of the surface analysis.

Aloft, the region was under prevailing northwest flow at $500 \mathrm{hPa}$ (Fig. 15). In comparing with Fig. 5 in KGD07, it is seen that the reanalyses (aside from 20CR; Fig. 15d) captured the pattern well, with a broad area of 30-40-kt flow downstream of an upper-level ridge axis that was located just west of the plotted domain. Minor nuances among the reanalyses included a weak short-wave trough in NARR (Fig. 15a) and separated maxima in the higher-resolution reanalyses (e.g., MERRA-2 and CFSR).

Proximity soundings at 0000 UTC 20 July 2004 were compared with the Grand Forks 2300 UTC RUC-2 sounding from T07 (Fig. 16; Table 4). While SBCAPE was $\sim 4000 \mathrm{~J} \mathrm{~kg}^{-1}$ in RUC-2 (Fig. 16a), NARR (Fig. 16b), and JRA-55 (Fig. 16c), other reanalyses had significantly less instability, similar to the 3 May 1999 case. The consideration of MLCAPE worsened the 
$\mathbf{A}$

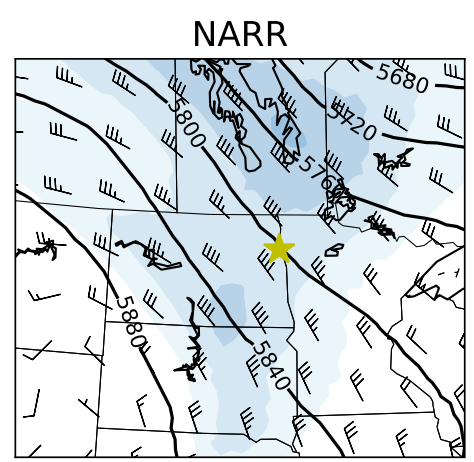

D

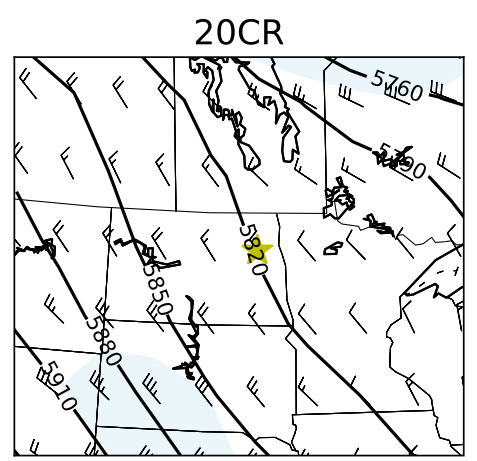

B

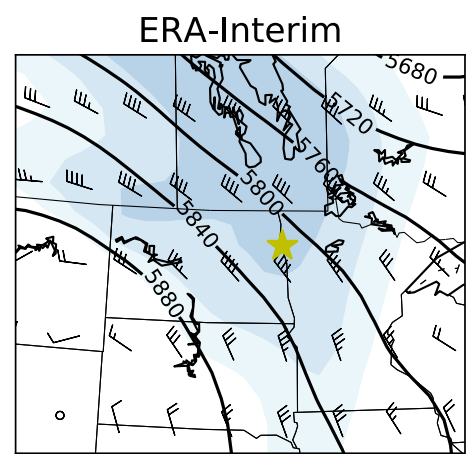

C

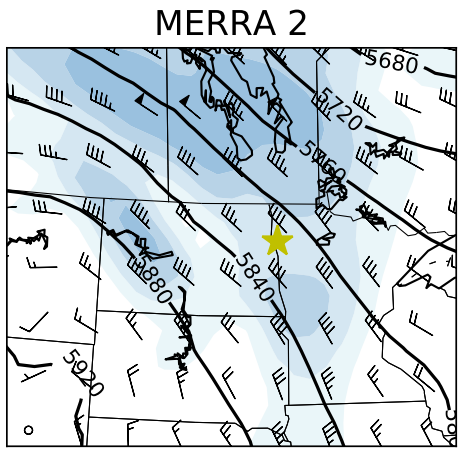

E

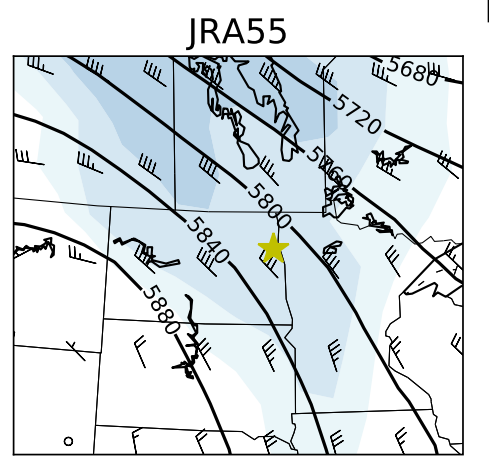

$\mathbf{F}$

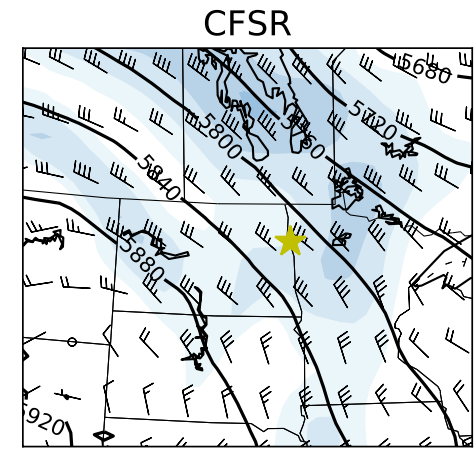

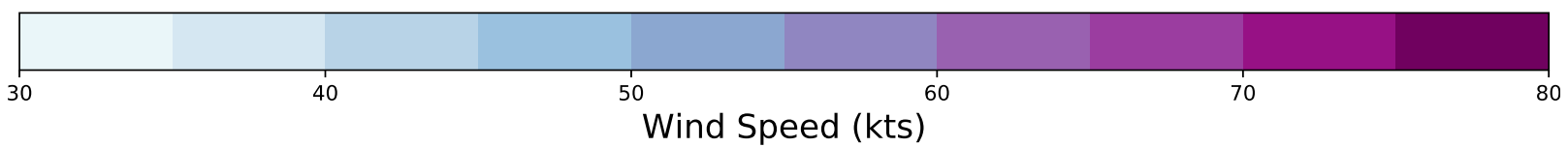

FIG. 15. As in Fig. 14, but for 500-hPa analyses. Contoured variables are as in Fig. 11.

comparison; the closest reanalysis (NARR) had a deficit of $\sim 1500 \mathrm{~J} \mathrm{~kg}^{-1}$. In this case, the primary problem was a lack of moisture throughout the boundary layer for the reanalyses. In light of earlier discussion about this event, evapotranspiration (as hypothesized in KGD07), problems with the boundary layer schemes, or some other cause was to blame.

From a kinematic perspective, this case was weaker than 3 May 1999; RUC-2 had 0-1-km SRH (ESRH) of $105(225) \mathrm{m}^{2} \mathrm{~s}^{-2}$, an EBWD of $22 \mathrm{kt}$, and 0-1-km BWD of $13 \mathrm{kt}$ (Table 4). With the exception of 20CR (Fig. 16e), which was too weak, other reanalyses performed well for fixed-height parameters such as 0-1-km SRH (85$130 \mathrm{~m}^{2} \mathrm{~s}^{-2}$ ) and $0-1-\mathrm{km}$ BWD (11-15kt). Larger variations were found when the effective layer was considered. For example, ESRH had a negative (low) bias with values from 96 to $179 \mathrm{~m}^{2} \mathrm{~s}^{-2}$, and EBWD ranged from 14 to $27 \mathrm{kt}$. Given that the effective layers were similar in this case, most of the variability must be attributed to differences in the wind field, which is expected provided the location of the soundings near a boundary.

\section{Discussion}

Discussing results in the context of other studies is difficult because of the suite of reanalyses used and the subset of cases investigated (proximity environments). NARR results can be compared with Gensini et al. (2014a). In broad terms, the current study encountered many of the same issues found in the prior work such as surface thermodynamic biases and poor performance for calculated quantities such as CIN. Unlike that study, differences in MLCAPE and SBCAPE for NARR were minor and NARR had good agreement with RUC-2 for STP. Correlations in this study were significantly higher ( 0.75 vs 0.12 for MLCAPE). This suggests that performance varies by environment given that Gensini et al. (2014a) investigated over 100000 observed soundings 
A

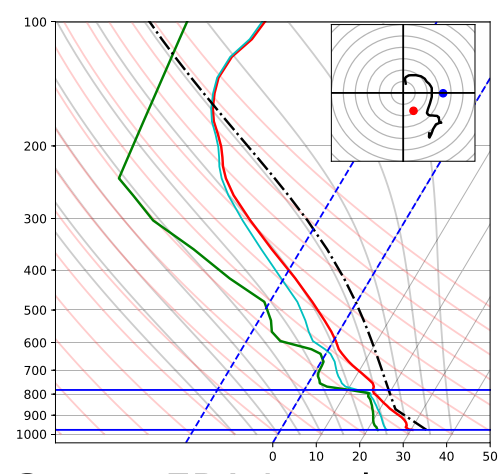

B

NARR

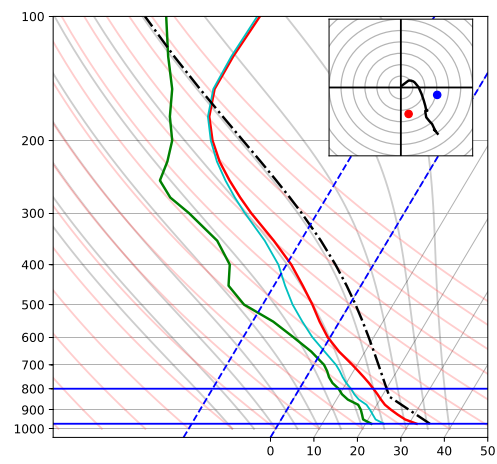

$\mathbf{E}$

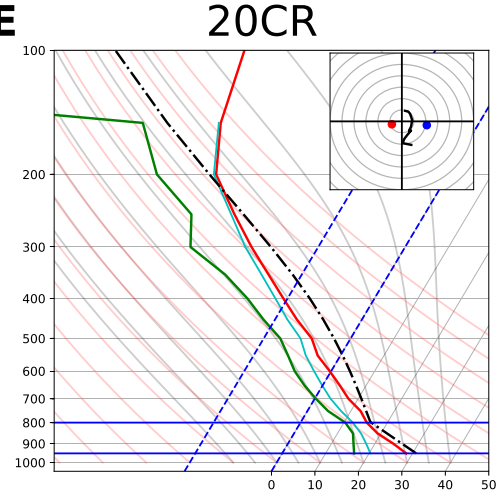

C ERA-Interim

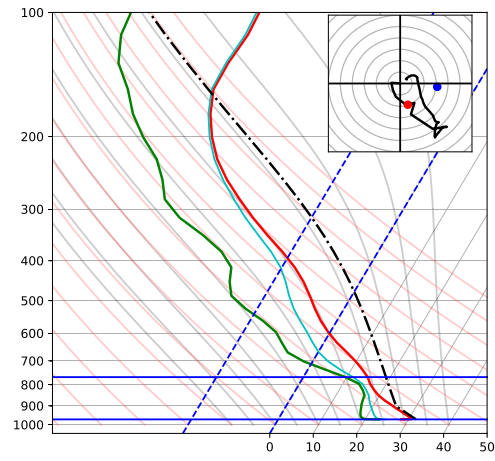

$\mathbf{F}$

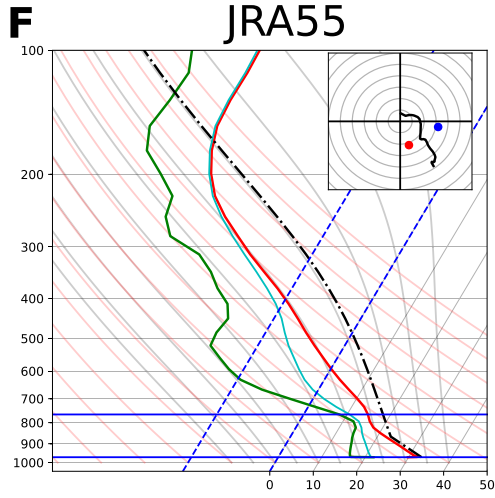

D MERRA 2

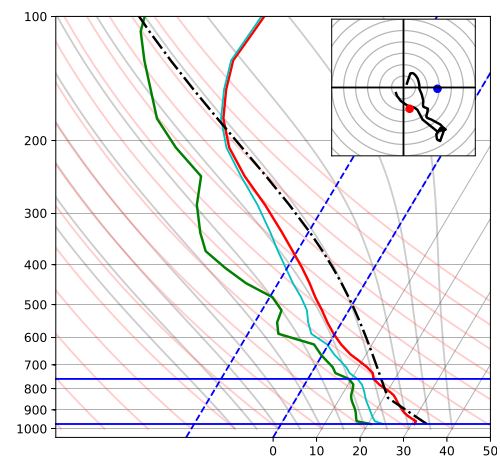

G

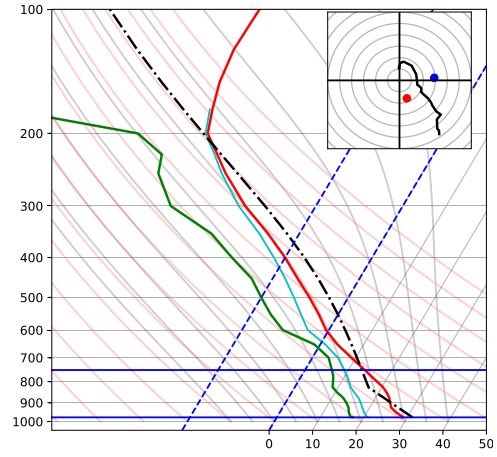

FIG. 16. As in Fig. 12, but for locations closest to GFK at 0000 UTC 19 Jul 2004.

regardless of whether convection occurred. Alternatively, the reliance on RUC-2 output for verification in the current study may intrinsically bias performance for the reanalyses. The argument against this latter possibility comes from studies, such as T03, that have documented the positive aspects of RUC-2 performance.

For all reanalyses, performance is tied to the ability of a reanalysis to reproduce the thermodynamic environment. NARR and JRA-55 had values of MLCAPE within the error bars of RUC-2 ( $<500 \mathrm{~J} \mathrm{~kg}^{-1}$; T03, Coniglio 2012) while all other reanalyses had significant negative biases. Since more recently developed convective parameters such as ESRH, SCP, and STP incorporate thermodynamic information, this in effect suppressed values of these parameters for many of the reanalyses (T03). Discrepancies in the thermodynamic environment may be explained by a number of factors. While the quantity of reanalyses and the variety of causes preclude an extensive analysis, an attempt was made to investigate several possible causes: resolution, surface and midlevel thermodynamic biases, and convective contamination (which may in part cause said biases).

The superior spatial and temporal grid spacing for NARR may have led to the improved representation of thermodynamic parameters. To test this theory, NARR was upscaled to a lower resolution by averaging grid 
TABLE 4. Select sounding parameters for the 19 Jul 2004 case. Parameters correspond to the soundings shown in Fig. 16.

\begin{tabular}{|c|c|c|c|c|c|c|c|c|}
\hline \multirow[b]{2}{*}{ Sounding } & \multirow[b]{2}{*}{$\operatorname{MLCAPE}\left(\mathrm{J} \mathrm{kg}^{-1}\right)$} & \multirow[b]{2}{*}{$\operatorname{SBCAPE}\left(\mathrm{J} \mathrm{kg}^{-1}\right)$} & \multirow[b]{2}{*}{$\operatorname{SBLCL}(\mathrm{m})$} & \multicolumn{2}{|c|}{$\mathrm{SRH}\left(\mathrm{m}^{2} \mathrm{~s}^{-2}\right)$} & \multicolumn{2}{|c|}{ BWD (kt) } & \multirow[b]{2}{*}{$\operatorname{MLCAPE}\left(\mathrm{J} \mathrm{kg}^{-1}\right)$} \\
\hline & & & & $0-1 \mathrm{~km}$ & $\overline{\text { Effective }}$ & $0-1 \mathrm{~km}$ & $\overline{\text { Sounding }}$ & \\
\hline RUC-2 & 3577 & 4022 & 1023 & 105 & 225 & 13 & 22 & 18.1 \\
\hline NARR & 2097 & 3843 & 1325 & 91 & 166 & 11 & 22 & 12.8 \\
\hline ERA-Interim & 1326 & 2289 & 373 & 85 & 96 & 11 & 14 & 3.1 \\
\hline MERRA-2 & 435 & 1121 & 717 & 105 & 124 & 11 & 15 & 2.2 \\
\hline 20CR (V2) & 1219 & 1393 & 1522 & 22 & 47 & 5 & 9 & 0 \\
\hline JRA-55 & 1683 & 4090 & 1032 & 98 & 157 & 14 & 27 & 12.9 \\
\hline CFSR & 942 & 1225 & 1494 & 130 & 179 & 15 & 27 & 4.4 \\
\hline
\end{tabular}

points and using only synoptic times $(1200,1800,0000$, and 0600 UTC). No statistically significant differences were found for almost all of the parameters. This implies that resolution differences are not the primary factor affecting the ability of a reanalysis to accurately portray the thermodynamic environment.

Because small variations in moisture and temperature can have a large impact on CAPE, biases in the thermodynamic properties were explored by generating composite soundings for the various storm types (not shown). Thermodynamic biases were evident for some of the reanalyses. To demonstrate this, box-and-whisker plots of biases for surface properties and 400-hPa temperatures are shown in Fig. 17. Many of the biases noted in the case studies are also present within the full dataset. For surface temperatures (Fig. 17a), notable reanalyses with biases exceeding the range of RUC-2 errors include NARR $\left(+1.5^{\circ} \mathrm{C}\right)$ and $20 \mathrm{CR}\left(-2.9^{\circ} \mathrm{C}\right)$. Smaller biases are found for surface moisture. While all reanalyses have slightly negative surface mixing ratios relative to RUC-2, only CFSR has a median that falls outside the errors quantified in T03 (Fig. 17b). Coniglio (2012) documented surface dewpoint biases for RUC-2 that were $1^{\circ}-2^{\circ} \mathrm{C}$ too moist. Median values for most reanalyses are $<1^{\circ} \mathrm{C}$ drier than RUC, which is an improvement from RUC-2 for surface moisture. The lone exception is CFSR, which is biased to be $2.5^{\circ} \mathrm{C}$ drier than RUC-2.

Midlevel temperature biases also impact calculations of CAPE for select reanalyses (Fig. 15c). Notably, MERRA-2 and 20CR have warm biases of $3^{\circ}$ and $1.5^{\circ} \mathrm{C}$, respectively, that reduce the lifted index and computed CAPE. Given that these reanalyses are also too cool at the surface (Fig. 17b), this is most likely an impact of convection occurring. While a full exploration of this issue is beyond the scope of this paper, it is worth noting that both of these reanalyses use the relaxed Arakawa-Schubert (Moorthi and Suarez 1992) convective parameterization. Common in the climate modeling community, a by-product of this choice is a diurnal cycle of convection that is closely tied to diurnal heating and production of CAPE (Lee et al. 2007).
For these reanalyses, CAPE effectively triggers convection earlier in the day and this 1) reduces the CAPE (Fig. 9a) and 2) introduces thermodynamic biases (Fig. 17c). In MERRA-2, for example, $70 \%$ of the cases had convective precipitation recorded within $6 \mathrm{~h}$ prior to the proximity soundings.

In summary, the reliance of reanalyses on parameterizations causes impacts on thermodynamic and kinematic parameters frequently used in convective studies. This was also noted in studies such as Gensini et al. (2014a). This leads one to ponder what impact this may have on climatological studies that use threshold values (e.g., MLCAPE $\geq 1000 \mathrm{~J} \mathrm{~kg}^{-1}$ ) to diagnose properties such as the frequency or trends in environments favorable for severe convection. Further complicating matters is the question of whether a user should calculate parameters such as CAPE or utilize the values provided by the reanalysis.

As an example of this conundrum, consider a user of ERA-Interim. The results of this study demonstrate that MLCAPE is biased to be low by $\sim 1000 \mathrm{~J} \mathrm{~kg}^{-1}$ for convective environments when calculated independently with SHARPpy. As mentioned in section 3, ERA-Interim uses an approximate form of CAPE that results in an $\sim 20 \%$ positive bias (ECMWF 2015 ). Utilizing the included values for CAPE in ERAInterim results in median values 547,193 , and $113 \mathrm{~J} \mathrm{~kg}^{-1}$ higher than the values calculated in this study for ML, $\mathrm{SB}$, and MU parcels, respectively. In conclusion, there are a number of choices that a user can make, and it is not immediately clear what the impact of those choices may be for climatological studies. What should be evident is that users should use standard methods so that results from different studies can be directly compared.

\section{Summary and conclusions}

The primary objective of this paper was to compare a suite of modern reanalyses with the T07 dataset of RUC-2 proximity soundings that largely represent 
A

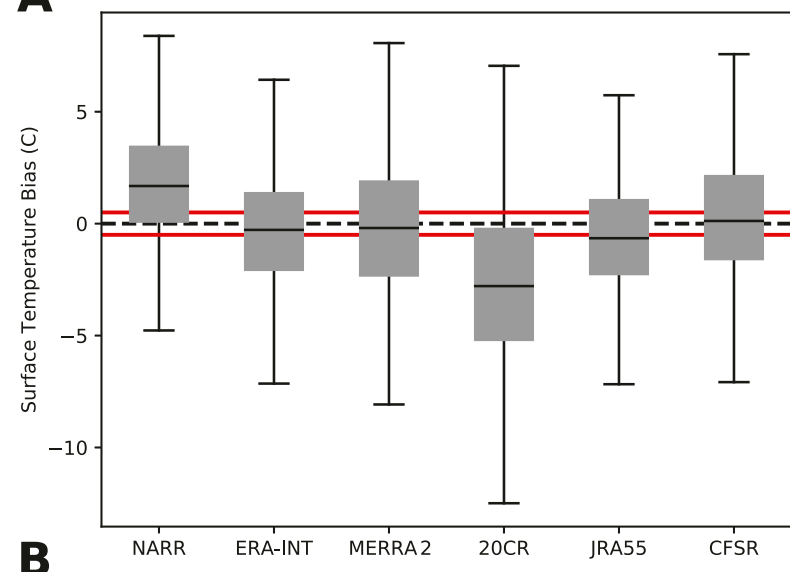

B
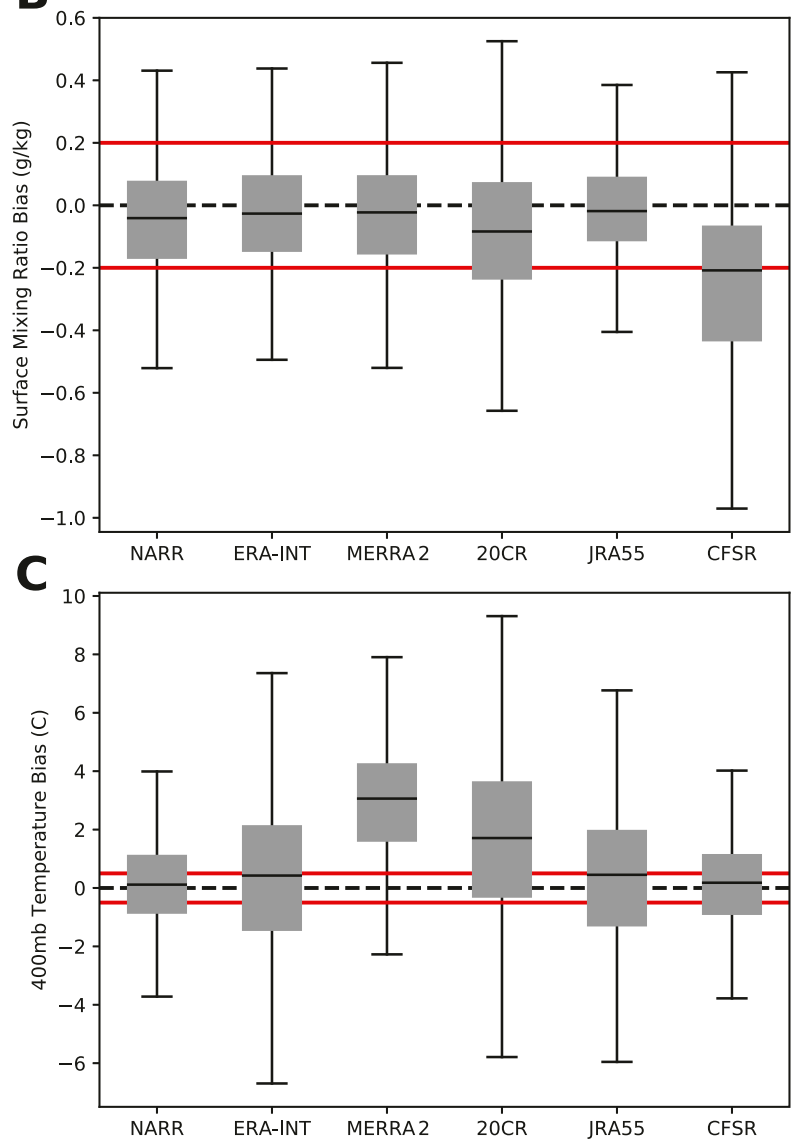

FIG. 17. Box-and-whisker plots of biases (reanalysis - RUC-2) for (a) surface mixing ratios, (b) surface temperatures, and (c) 400-hPa temperatures. Red lines indicate the typical error range for RUC-2, as described in T03.

supercell environments. Besides investigating biases in commonly used convective indices, the study explored whether the reanalyses could reproduce the results of $\mathrm{T} 03$ and T07. To that end, a common sounding-analysis package (SHARPpy) was used so that direct intercomparisons could be made. Provided below is a list of the major findings:

- Thermodynamic performance varied across the reanalyses. Only NARR and JRA-55 had CAPE values within the error bars of RUC-2. Although NARR and JRA-55 were technically biased low (negatively) for MLCAPE, these values may be more representative given the documented high (positive) biases for RUC-2.

- Biases in CAPE can be directly related to issues in the thermodynamic fields. Some reanalyses such as MERRA-2 and 20CR are biased low (negatively) because of midlevel temperatures that are too warm, presumably as a result of convective contamination, whereas CFSR was impacted by negative biases for surface moisture.

- Thermodynamic performance negatively affects reanalyses for composite parameters and kinematic parameters that indirectly incorporate thermodynamic information via the effective layer. As a result, all reanalyses except NARR and JRA-55 were biased low (negatively) for parameters such as ESRH, SCP, and STP.

- The majority of reanalyses reasonably reproduced the kinematic environment with nearly uniform correlations for the various parameters. The lone exception was 20CR, which had significant negative biases. Regardless of the reanalysis examined, performance was better for fixed-level shear parameters than for ESRH.

- The net result of negative biases led to more overlapped distributions when the analysis was segregated by storm type. Although no reanalysis can exactly reproduce the work of T03 and T07, many of the reanalyses can broadly distinguish between environments that are significantly tornadic versus nontornadic. Better segregation is found for fixed-layer parameters than for those that use the effective layer.

No effort is made to objectively or subjectively rank the reanalyses. As the results show, performance varies across these datasets. In broad terms, JRA-55 and NARR do the best job representing the thermodynamic environment, and this performance has a positive impact on results for composite parameters and kinematic properties that involve the effective layer. Despite this result, analysis segregated by storm type demonstrates the reanalyses' ability to broadly distinguish between significantly tornadic/severe environments and those that are unlikely to produce supercells.

The lone exception to the above statement is $20 \mathrm{CR}$, which performed poorly across all categories. It should be stressed that for this reanalysis the ensemble mean 
field was used, creating a somewhat unfair comparison. While this decision was made on the premise that no a priori knowledge of an event should be needed, it is conceivable that a user could arbitrarily pick ensemble members that better match the available observations.

The presented work offers itself as an initial intercomparison of reanalyses against a well-documented dataset of severe convective cases. Outstanding questions include how representative these results are for other regions of the world that are less constrained by observations and how these reanalyses represent climatological properties such as the number of days exceeding a given threshold. These questions as well as a climatological intercomparison of reanalyses will be the subject of future activities.

Acknowledgments. The authors acknowledge Richard Thompson and Roger Edwards for kindly providing the RUC-2 proximity soundings. Kaley King and Christy Wall are also thanked for providing feedback on a draft of the paper. Three anonymous reviewers provided a number of helpful suggestions that improved the clarity of the paper. NARR data were provided online by the NOAA/OAR/ESRL PSD (http://www.esrl.noaa.gov/ $\mathrm{psd} /$ ). Other reanalyses, including CFSR, JRA-55, ERAInterim, and 20CR, were carried out by their respective agencies; however, data were obtained online from the Research Data Archive at the NCAR Computational and Information Systems Laboratory (https://rda.ucar. edu/datasets). MERRA-2 data were acquired online from NASA GES DISC (https://disc.sci.gsfc.nasa.gov/). This research was supported by National Science Foundation Project IIA-1355466 at the University of North Dakota.

\section{REFERENCES}

Allen, J. T., and D. J. Karoly, 2014: A climatology of Australian severe thunderstorm environments 1979-2011: Inter-annual variability and ENSO influence. Int. J. Climatol., 34, 81-97, https://doi.org/10.1002/joc.3667.

Benjamin, S. G., and Coauthors, 2004: An hourly assimilation-forecast cycle: The RUC. Mon. Wea. Rev., 132, 495-518, https://doi.org/ 10.1175/1520-0493(2004)132<0495:AHACTR>2.0.CO;2.

Blamey, R. C., C. Middleton, C. Lennard, and C. J. C. Reason, 2016: A climatology of potential severe convective environments across South Africa. Climate Dyn., 49, 2161-2178, https://doi.org/10.1007/s00382-016-3434-7.

Blumberg, W. G., K. T. Halbert, T. A. Supinie, P. T. Marsh, R. L. Thompson, and J. A. Hart, 2017: SHARPpy: An open source sounding analysis toolkit for the atmospheric sciences. Bull. Amer. Meteor. Soc., 98, 1625-1636, https://doi.org/10.1175/ BAMS-D-15-00309.1.

Brooks, H. E., 2009: Proximity soundings for severe convection for Europe and the United States from reanalysis data. Atmos. Res., 93, 546-553, https://doi.org/10.1016/j.atmosres.2008.10.005.
— J. W. Lee, and J. P. Craven, 2003: The spatial distribution of severe thunderstorm and tornado environments from global reanalysis data. Atmos. Res., 67-68, 73-94, https://doi.org/ 10.1016/S0169-8095(03)00045-0.

, A. R. Anderson, K. Riemann, I. Ebbers, and H. Flachs, 2007: Climatological aspects of convective parameters from the NCAR/ NCEP reanalysis. Atmos. Res., 83, 294-305, https://doi.org/10.1016/ j.atmosres.2005.08.005.

Bunkers, M. J., B. A. Klimowski, J. W. Zeitler, R. L. Thompson, and M. L. Weisman, 2000: Predicting supercell motion using a new hodograph technique. Wea. Forecasting, 15, 61-79, https://doi.org/ 10.1175/1520-0434(2000)015<0061:PSMUAN >2.0.CO;2.

Burgess, D. W., M. A. Magsig, J. Wurman, D. C. Dowell, and Y. Richardson, 2002: Radar observations of the 3 May 1999 Oklahoma City tornado. Wea. Forecasting, 17, 456-471, https://doi.org/ 10.1175/1520-0434(2002)017<0456:ROOTMO > 2.0.CO;2.

Compo, G. P., and Coauthors, 2011: The Twentieth Century Reanalysis Project. Quart. J. Roy. Meteor. Soc., 137, 1-28, https:// doi.org/10.1002/qj.776.

Coniglio, M. C., 2012: Verification of RUC 0-1-h forecasts and SPC mesoscale analyses using VORTEX2 soundings. Wea. Forecasting, 27, 667-683, https://doi.org/10.1175/WAF-D-11-00096.1.

Davies, J. M., 1993: Small tornadic supercells in the central plains. Preprints, 17th Conf. on Severe Local Storms, St. Louis, MO, Amer. Meteor. Soc., 305-309.

- 2004: Estimations of CIN and LFC associated with tornadic and nontornadic supercells. Wea. Forecasting, 19, 714-726, https:// doi.org/10.1175/1520-0434(2004)019<0714:EOCALA >2.0.CO;2.

Dee, D. P., and Coauthors, 2011: The ERA-Interim reanalysis: Configuration and performance of the data assimilation system. Quart. J. Roy. Meteor. Soc., 137, 553-597, https://doi.org/ 10.1002/qj.828.

Doswell, C. A., III, and E. N. Rasmussen, 1994: The effect of neglecting the virtual temperature correction on CAPE calculations. Wea. Forecasting, 9, 625-629, https://doi.org/10.1175/ 1520-0434(1994)009<0625:TEONTV >2.0.CO;2.

ECMWF, 2015: New EFI parameters for forecasting severe convection. ECMWF Newsletter, No. 144, ECMWF, Reading, United Kingdom, 27-32, https:/www.ecmwf.int/ sites/default/files/elibrary/2015/17324-new-efi-parametersforecasting-severe-convection.pdf.

Edwards, R., and R. L. Thompson, 2009: Comments on "The North Dakota tornadic supercells of 18 July 2004: Issues concerning high LCL heights and evapotranspiration." Wea. Forecasting, 24, 1149-1158, https://doi.org/10.1175/2009WAF2222204.1.

Gensini, V. A., and W. S. Ashley, 2011: Climatology of potentially severe convective environments from North American regional reanalysis. Electron. J. Severe Storms Meteor., 6 (8), http://www. ejssm.org/ojs/index.php/ejssm/article/viewArticle/85.

, T. L. Mote, and H. E. Brooks, 2014a: Severe-thunderstorm reanalysis environments and collocated radiosonde observations. J. Appl. Meteor. Climatol., 53, 742-751, https://doi.org/ 10.1175/JAMC-D-13-0263.1.

- C. A. Ramseyer, and T. L. Mote, 2014b: Future convective environments using NARCCAP. Int. J. Climatol., 34, 16991705, https://doi.org/10.1002/joc.3769.

Halbert, K. T., W. Blumberg, and P. Marsh, 2015: SHARPpy: Fueling the Python cult. Fifth Symp. on Advances in Modeling and Analysis Using Python, Phoenix AZ, Amer. Meteor. Soc., 402, https://ams.confex.com/ams/95Annual/webprogram/ Paper270233.html.

Hart, J. A., and W. Korotky, 1991: The SHARP workstation vl.50 user's guide. NOAA/National Weather Service, 30 pp. 
[Available from NWS Eastern Region Headquarters, 630 Johnson Ave., Bohemia, NY 11716.]

Johns, R. H., J. M. Davies, and P. M. Leftwich, 1993: Some wind and instability parameters associated with strong and violent tornadoes. Part II: Variations in the combinations of wind and instability parameters. The Tornado: Its Structure, Dynamics, Hazards, and Prediction, Geophys. Monogr., Vol. 79, Amer. Geophys. Union, 583-590.

Kalnay, E., and Coauthors, 1996: The NCEP/NCAR 40-Year Reanalysis Project. Bull. Amer. Meteor. Soc., 77, 437-471, https:// doi.org/10.1175/1520-0477(1996)077<0437:TNYRP>2.0.CO;2.

Kellenbenz, D. J., T. J. Grafenauer, and J. M. Davies, 2007: The North Dakota tornadic supercells of 18 July 2004: Issues concerning high LCL heights and evapotranspiration. Wea. Forecasting, 22, 1200-1213, https://doi.org/10.1175/2007WAF2006109.1.

Kennedy, A., X. Dong, B. Xi, S. Xie, Y. Zhang, and J. Chen, 2011: A comparison of MERRA and NARR reanalyses with the DOE ARM SGP data. J. Climate, 24, 4541-4557, https://doi.org/ 10.1175/2011JCLI3978.1.

Kobayashi, S., and Coauthors, 2015: The JRA-55 reanalysis: General specifications and basic characteristics. J. Meteor. Soc. Japan, 93, 5-48, https://doi.org/10.2151/jmsj.2015-001.

Lee, M-I., and Coauthors, 2007: An analysis of the warm-season diurnal cycle over the continental United States and northern Mexico in general circulation models. J. Hydrometeor., 8, 344366, https://doi.org/10.1175/JHM581.1.

Lepore, C., D. Veneziano, and A. Molini, 2015: Temperature and CAPE dependence of rainfall extremes in the eastern United States. Geophys. Res. Lett., 42, 74-83, https://doi.org/10.1002/ 2014GL062247.

Markowski, P. M., 2002: Mobile mesonet observations on 3 May 1999. Wea. Forecasting, 17, 430-444, https://doi.org/10.1175/ 1520-0434(2002)017<0430:MMOOM > 2.0.CO;2.

—, C. Hannon, J. Frame, E. Lancaster, A. Pietrycha, R. Edwards, and R. L. Thompson, 2003: Characteristics of vertical wind profiles near supercells obtained from the Rapid Update Cycle. Wea. Forecasting, 18, 1262-1272, https://doi.org/10.1175/15200434(2003)018<1262:COVWPN >2.0.CO;2.

Marsh, P. T., H. E. Brooks, and D. J. Karoly, 2007: Assessment of the severe weather environment in North America simulated by a global climate model. Atmos. Sci. Lett., 8, 100-106, https:// doi.org/10.1002/asl.159.

- —, and — 2009: Preliminary investigation into the severe thunderstorm environment of Europe simulated by the Community Climate System Model 3. Atmos. Res., 93, 607618, https://doi.org/10.1016/j.atmosres.2008.09.014.

Mesinger, F., and Coauthors, 2006: North American Regional Reanalysis. Bull. Amer. Meteor. Soc., 87, 343-360, https://doi.org/ 10.1175/BAMS-87-3-343.

Moorthi, S., and M. Suarez, 1992: Relaxed Arakawa-Schubert: A parameterization of moist convection for general circulation models. Mon. Wea. Rev., 120, 978-1002, https://doi.org/10.1175/ 1520-0493(1992)120<0978:RASAPO > 2.0.CO;2.
Rasmussen, E. N., 2003: Refined supercell and tornado forecast parameters. Wea. Forecasting, 18, 530-535, https://doi.org/ 10.1175/1520-0434(2003)18<530:RSATFP > 2.0.CO;2.

— sounding-derived supercell and tornado forecast parameters. Wea. Forecasting, 13, 1148-1164, https://doi.org/10.1175/15200434(1998)013<1148:ABCOSD > 2.0.CO;2.

Reames, L. J., 2017: Diurnal variations in severe weather forecast parameters of Rapid Update Cycle-2 tornado proximity environments. Wea. Forecasting, 32, 743-761, https://doi.org/ 10.1175/WAF-D-16-0029.1.

Rienecker, M. M., and Coauthors, 2011: MERRA: NASA's Modern-Era Retrospective Analysis for Research and Applications. J. Climate, 24, 3624-3648, https://doi.org/10.1175/ JCLI-D-11-00015.1.

Roebber, P. J., D. M. Schultz, and R. Romero, 2002: Synoptic regulation of the 3 May 1999 tornado outbreak. Wea. Forecasting, 17, 399-429, https://doi.org/10.1175/1520-0434(2002) 017<0399:SROTMT>2.0.CO;2.

Romero, R., M. Gayà, and C. A. Doswell III, 2007: European climatology of severe convective storm environmental parameters: A test for significant tornado events. Atmos. Res., 83, 389-404, https://doi.org/10.1016/j.atmosres.2005.06.011.

Saha, S., and Coauthors, 2010: The NCEP Climate Forecast System Reanalysis. Bull. Amer. Meteor. Soc., 91, 1015-1057, https:// doi.org/10.1175/2010BAMS3001.1.

Sherburn, K., M. Parker, J. King, and G. Lackmann, 2016: Composite environments of severe and nonsevere high-shear, lowCAPE convective events. Wea. Forecasting, 31, 1899-1927, https://doi.org/10.1175/WAF-D-16-0086.1.

Stensrud, D. J., and S. J. Weiss, 2002: Mesoscale model ensemble forecasts of the 3 May 1999 tornado outbreak. Wea. Forecasting, 17, 526-543, https://doi.org/10.1175/1520-0434(2002) 017<0526:MMEFOT>2.0.CO;2.

Thompson, R. L., and R. Edwards, 2000: An overview of environmental conditions and forecast implications of the 3 May 1999 tornado outbreak. Wea. Forecasting, 15, 682-699, https://doi.org/ 10.1175/1520-0434(2000)015<0682:AOOECA > 2.0.CO;2.

,-- J. A. Hart, K. L. Elmore, and P. Markowski, 2003: Close proximity soundings within supercell environments obtained from the Rapid Update Cycle. Wea. Forecasting, 18, 1243-1261, https://doi.org/10.1175/1520-0434(2003)018<1243: CPSWSE $>2.0 . \mathrm{CO} ; 2$.

_ C. M. Mead, and R. Edwards, 2007: Effective storm-relative helicity and bulk shear in supercell thunderstorm environments. Wea. Forecasting, 22, 102-115, https://doi.org/10.1175/ WAF969.1.

Trapp, R. J., N. S. Diffenbaugh, H. E. Brooks, M. E. Baldwin, E. D. Robinson, and J. S. Pal, 2007: Changes in severe thunderstorm environment frequency during the 21st century caused by anthropogenically enhanced global radiative forcing. Proc. Natl. Acad. Sci. USA, 104, 19719-19723, https://doi.org/ 10.1073/pnas.0705494104. 